Rhode Island College

Digital Commons @ RIC

$1-1-2010$

\title{
A Gender Specific Educational Pilot Program to Improve Women's Awareness About Heart Disease and Their Risk
}

Debra Lee Campo

Rhode Island College

Follow this and additional works at: https://digitalcommons.ric.edu/etd

Part of the Public Health and Community Nursing Commons

\section{Recommended Citation}

Campo, Debra Lee, "A Gender Specific Educational Pilot Program to Improve Women's Awareness About Heart Disease and Their Risk" (2010). Master's Theses, Dissertations, Graduate Research and Major Papers Overview. 210.

https://digitalcommons.ric.edu/etd/210

This Major Paper is brought to you for free and open access by the Master's Theses, Dissertations, Graduate Research and Major Papers at Digital Commons @ RIC. It has been accepted for inclusion in Master's Theses, Dissertations, Graduate Research and Major Papers Overview by an authorized administrator of Digital Commons @ RIC. For more information, please contact digitalcommons@ric.edu. 


\section{A GENDER SPECIFIC EDUCATIONAL PILOT PROGRAM}

TO IMPROVE WOMEN'S AWARENESS ABOUT

HEART DISEASE AND THEIR RISK

A Major Paper Presented

By

Debra Lee Campo

Approved:

Committee Chairperson

Committee Members
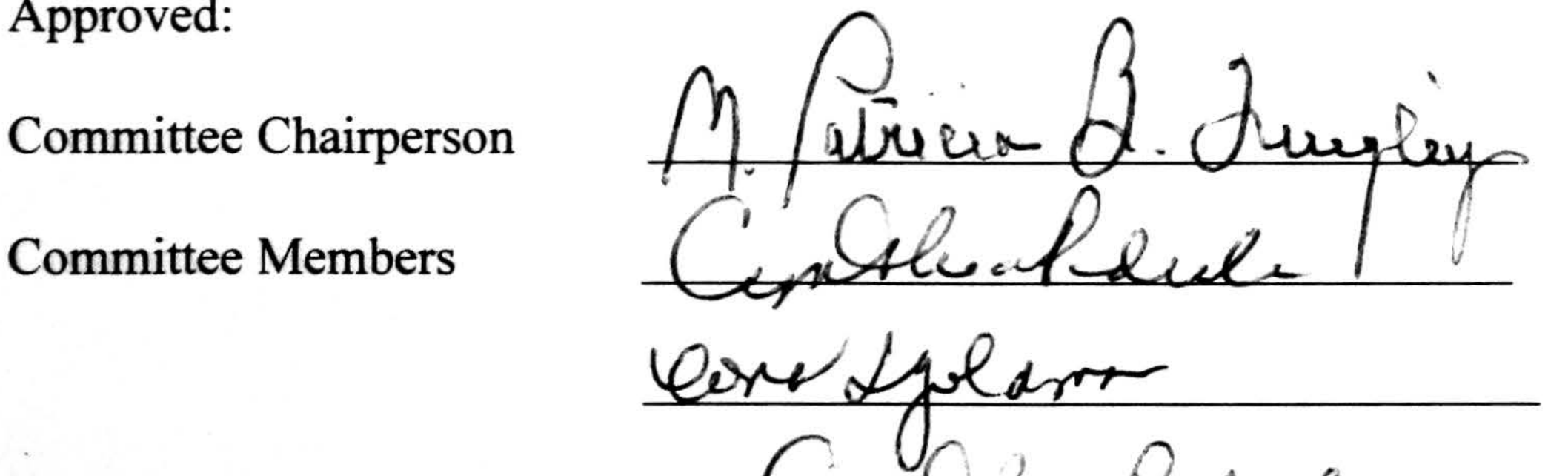

Director of Master's Program
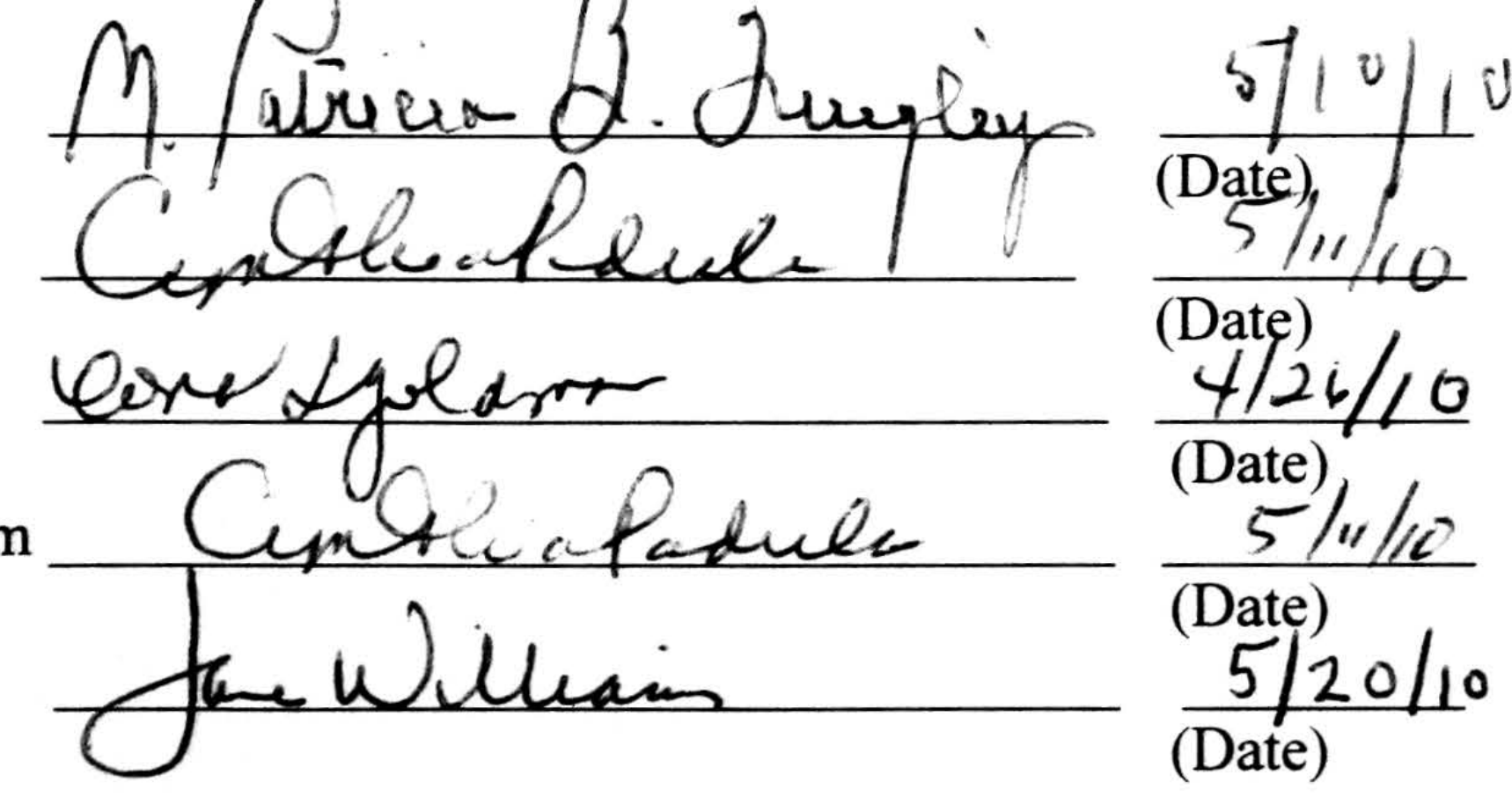

Dean, School of Nursing

$$
\begin{aligned}
& \frac{5 / 11 / 10}{(\text { Date })} \\
& \frac{5 / 20 / 10}{\text { (Date) }}
\end{aligned}
$$




\section{A GENDER SPECIFIC EDUCATIONAL PILOT PROGRAM TO IMPROVE WOMEN'S AWARENESS ABOUT \\ HEART DISEASE AND THEIR RISK}

$$
\text { by }
$$

$$
\text { Debra Lee Campo }
$$
A Major Paper Submitted in Partial Fulfillment
of the Requirements for the Degree of
Master of Science in Nursing
in

The School of Nursing

Rhode Island College

2010 


\section{Abstract}

Cardiovascular disease is the number one killer of women in the U.S. While public health campaigns have made great progress improving women's awareness of heart disease as the leading cause of death, most women do not understand the magnitude of cardiovascular risks. Some women are not aware that heart disease is the greatest threat to their health and to the health of their loved ones (Thanavaro, Moore, Anthony, Narsavage, \& Delicath, 2006). Women continue to have longer delays in seeking medical treatment and have a higher mortality/morbidity rate when compared to men. Disparities also continue to persist among racial/ethnic and lower socio-economic groups (Christian, Rosamond, White, \& Mosca, 2007).The purpose of this pilot educational program was to increase women's knowledge and awareness about heart disease, its risk factors, and personal risk by empowering them with the knowledge to choose healthier lifestyles for themselves and their family. The program targeted women over the age of eighteen and the accessible population for this health promotion program was the female staff at an assisted living community located in Northern Rhode Island and their guest. The program consisted of four educational interventions delivered once a week for four weeks. While attending all sessions was encouraged, it was not mandatory. Although attendance was small, the results from pre and post tests demonstrated that a small, nurse led intervention led to dramatic improvement in knowledge level of all participants. The Advanced Practice Public Health Nurse (APPHN) plays a key role in the fight against CVD. As diabetes, obesity, and life expectancy continue to rise, a competent workforce will be needed to educate and promote the cardiac health of the population. As specialists in community health nursing, APPHN's practice in a variety of settings and are uniquely positioned to have a wide range of influence, making them a key force in meeting this challenge. 
Table of Contents. Page

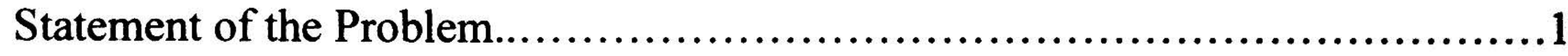

Literature Review.........................................................

Theoretical Framework .........................................................11

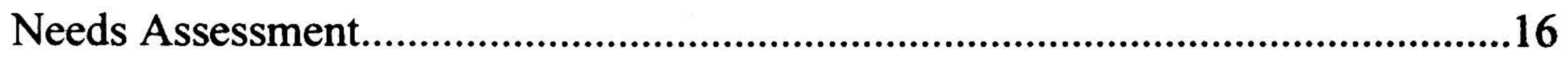

Program Development and Implementation..................................29

Program Evaluation..............................................................

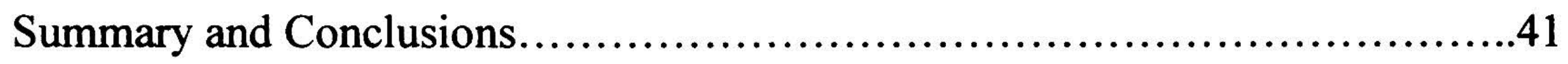

Recommendations and Implications for Advanced Practice Nursing.............46

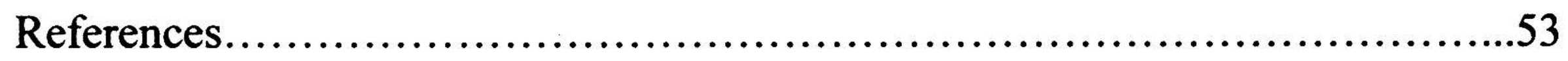

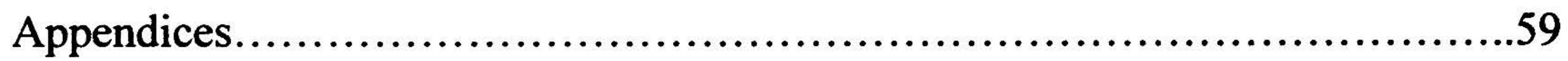


A Gender Specific Educational Pilot Program To Improve Women's Awareness About Heart Disease and Their Risk

Statement of the Problem

Heart disease has been the number one cause of death in the U.S. for more than a century. Presently, an estimated 80,000,000 American adults have some form of cardiovascular disease (CVD) and $38,100,000$ are estimated to be age 60 or older (American Heart Association [AHA], 2009). In 2005, heart disease killed more women than cancer, chronic lower respiratory diseases, Alzheimer's disease, accidents and diabetes combined (AHA). Based on 2005 death rates, CVD caused about one death per minute among women, or approximately 455,000 (52.6\%) female deaths in 2005 . In comparison, breast cancer, which is perceived by women as a major cause of their death, claimed the lives of 41,116 women in the same year (AHA). Although CVD is more common in older adults, more that $148,000(17 \%)$ of Americans who died of CVD in 2004 were younger than age 65 years (Centers for Disease Control [CDC], 2008). Heart disease and stroke also are the leading causes of disability in the U.S. workforce. Nearly one million people are disabled from strokes alone (CDC). Moreover, CVD disproportionately afflicts African American and Hispanic women (Christian, Mochari, \& Mosca, 2005). Women in lower income and education levels and without health insurance also have an increased risk of CVD morbidity and mortality (Finkelstein, Khavjou, Mobley, Haney, \& Will, 2004).

About a half of all deaths related to CVD are caused by heart attacks (Lefler, 2002). Furthermore, mortality rates for women who suffer from an acute myocardial infarction 
(AMI) are significantly higher than in men: $42 \%$ women versus $24 \%$ of men will die within one year after their AMI (Lefler). Large clinical trials have demonstrated that if patients receive care promptly, therapies are effective in reducing or completely negating the extent of damage to the myocardium. However, new advances in medical treatments are only useful within a narrow time frame; therefore, both men and women must seek treatment immediately after the onset of symptoms for best outcomes (Lefler). Many research studies have found that most patients do not seek medical treatment for at least two hours, and frequently, four or more hours after the onset of symptoms. The majority of this delay in treatment lies in the patient's decision making processes. Women, especially those older than 65 years, delay longer than do men before seeking medical treatment for symptoms of an AMI. The research also indicates that one of the most significant reasons for the delay is the atypical presentation of AMI in women (Lefler). As a result, women are unable to label their symptoms as cardiac, thus delay seeking treatment. Women are highly under-treated and under-diagnosed because often, instead of typical chest pain, they may have arm pain, neck and back pain, palpitations, sweating, dizziness, skipped heartbeats and abdominal pain as presenting symptoms (Lefler). Because research has focused on symptoms primarily of men, both women and healthcare providers may fail to recognize women's different symptoms as cardiac in nature, which results in a delay of treatment (Lefler).

While there is presently a lack of consensus among researchers about the reason women delay medical treatment for an AMI, studies have shown that women have a lower perception of personal risk for heart attack than men, which may account for their 
delay (Lefler, 2004). A 2004 survey indicated that when women were asked what the leading cause of death among women, more than $50 \%$ answered incorrectly (US Department of Health \& Human Services [USDHHS], About the Heart Truth). Furthermore, women commonly believe that preventing heart disease can be postponed. They believe that they can focus on prevention in their 50's, or after other life priorities, like raising children are less needed (Jacobs \& Eckel, 2005). A more recent 2006 survey found that while women are more aware of HD as the number one killer, many still do not acknowledge their risk (USDHHS, About the Heart Truth). And, while surveys show that women's fear of heart disease has almost doubled since 2002, breast cancer remains the single most feared disease (USDHHS).

Moreover, the burden of heart disease is staggering. The estimated direct and indirect cost of CVD, in total for 2008, is $\$ 475.3$ billion (AHA, 2009). As the "baby boom" population enters the peak heart disease years, the cost of CVD is likely to increase dramatically over the next several decades (Goff et al., 2007). Heart disease and stroke contribute greatly to the burden of our health care system, yet they are also among the most preventable. Leading a healthy lifestyle greatly reduces a person's risk of developing heart disease or stroke (CDC, 2008). Advanced practice nurses (APNs) play a key role in educating and promoting a healthy lifestyle as well as in improving the public's health and reducing the financial burden of our health care system. Also, APNs are significant in identifying and teaching women at highest risk for delay and increasing one's perception of risk to AMI, consequently reducing delays for women at risk. 


\section{Literature Review}

\section{Epidemiology/Delay in Treatment}

CVD is the leading cause of death among women in the United States. While the total deaths due to CVD among men decreased from 1979 to 2001, the number of deaths among women dying of CVD has remained the same or has increased (Christian et al., 2007). There is also a substantial disparity in prevalence, morbidity, and mortality of heart disease and stroke among racial/ethnic groups (Christian et al.). Moreover, most Americans have multiple risk factors, with the prevalence greatest among ethnic minorities and those of lower socioeconomic status. Black and Hispanic women are more likely to be diabetic, physically inactive, overweight, and obese compared with white women (Christian et al.).

Research indicates a relationship between mortality and delay time. To determine the cause for delay, in a study by Gurwitz et al. 1997, researchers performed chart reviews on 2409 patients in 37 Minnesota hospitals, they revealed that 969 (40\%) delayed presentation to the hospital for more than six hours after the onset of symptoms. In this study, it was demonstrated that factors associated with prolonged delay included advanced age and female sex and that women were significantly more likely to delay than men. The study showed factors that may explain why women delay longer than men including age differences between men and women, co morbidities, symptoms, social support, and insurance issues. Their recommendations were to target women for interventions to increase awareness of risk factors and prompt response to symptoms. Furthermore, Gurwitz et al., found that patients who did not have a living spouse, who 
lived alone, who resided in a long term care facility, or who were retired delayed more often than other patients. Patients with a history of hypertension or congestive heart failure were more likely to delay. Those whose symptoms developed between the times of 6:00pm and 11:59pm and between midnight and 5:59am had the greatest risk for delay compared with patients whose symptoms developed between 6:00am and 11:59pm (Gurwitz et al.).

Leizorovicz, Haugh, Mercier \& Boissel (1997) studied a total of 198 mobile emergency units in 15 European countries and in Canada. This randomized study of 5469 patients compared delay time in pre-hospital and hospital thrombolytic therapy. Delay between onset of symptoms and calling for an ambulance was significantly longer for female patients, older patients $(>65)$, those who had experienced pain within the previous 24 hours, and those with pulmonary edema. The delay was significantly shorter in patients with previous MIs. The study recommended more focus on patients who are likely to be late callers i.e., women and those over 65 years of age. Researchers of another study in the UK, interviewed 313 men and women who survived an MI (Leslie, Urie, Hooper \& Morrison, 2000). Their medical charts were reviewed between October 1994 and December 1996 to determine the cause of delay. Only $25 \%$ of all subjects made a call for medical help within one hour of the onset of symptoms, compared to $41 \%$ who called within 2 hours, and $60 \%$ called within four hours. In a study involving $52 \%$ of Quebec's acute care hospitals, data was collected on 8917 patients admitted with suspected MI. Women and older patients presented significantly later after symptom 
onset than men and younger patients, and patients with diabetes presented later than those without diabetes (Brophy, Diodati, Bogaty \& Theroux, 1998).

Research demonstrates that prompt treatment can negate the extent of damage to the myocardium. In a study of 1791 patients during 1994 to 2001 regarding delay times and impact on primary angioplasty, results suggested that every minute in delay affected the one year mortality (DeLuca, Suryapranata, Ottervanger, Elliott \& Antmen, 2004). This study found that the risk of death after one year increased by $7.5 \%$ for each 30 minute delay.

In a meta-synthesis of 48 studies by Lefler \& Bondy (2004), significant factors for delay were categorized as clinical in nature, socio-demographic variables, or psychosocial factors. The great majority of studies that examined clinical factors noted the significance that atypical presenting symptoms had on increasing pre-hospital delay. From this meta-synthesis, 27 of the 48 reports discussed psychosocial reasons for treatment delay. The most significant reason was the incorrect interpretation and attribution of presenting symptoms. Twelve investigations supported the assumption that patients who correctly attributed their presenting symptoms to their hearts had decreased delay intervals. It was found that $38 \%$ of women compared to $25 \%$ of men will die within one year after their AMI. Women were found to delay longer than men in seeking treatment and older females had the longest delays. Several studies also indicated that women were more likely to have prodromal and atypical symptoms, demonstrating that women have difficulty labeling their symptoms as cardiac, resulting in delay. It was also supported that women do not perceive themselves as much at risk for heart attack, and 
that the media has driven a social construction of the male norm for heart disease, promoting the idea that women are not the "type of person" to have a heart attack. Women (76\%) identified cancer, particularly breast cancer, as their most serious threat. The socio-demographic and temporal factors identified in this synthesis affecting delay time were listed according to the frequency of the study: female gender, older age, minority groups, low income, lower education, living alone, after routine office hours, and insurance coverage (Lefler \& Bondy). In the Rapid Early Action for Coronary Treatment (REACT) trial, the largest theoretically grounded, randomized controlled trial yet undertaken, mass media, public education and other methods to increase knowledge and awareness of heart attack, unfortunately, did not reduce delay time (Lefler, 2002). A possible explanation is that while consciousness-raising education and media campaigns affect awareness about causes, consequences, and cures for a particular problem, if the population is not prepared to take action, or do not perceive themselves to be vulnerable, they will not be served by these prevention programs (Lefler \& Bondy, 2004).

Roberts (2007) pointed out that data from 155,565 women and 229,313 men ages 3089 entered into the National Registry of Myocardial Infarction between1994-1998 indicated overall in-hospital mortality of $16.7 \%$ in women and $11.5 \%$ in men. Among patients less than 50 years old, women's mortality rate was more than twice that of men ( $6.1 \%$ vs. $2.9 \%)$, but the difference in mortality was no longer significant after the age of 74. In a study by McDonald et al., (2006), patients treated within one hour after (AMI) symptom onset had $40 \%$ less myocardial damage than patients treated 4-6 hours after symptom onset. And in a study by Canto et al. (2007), women were significantly less 
likely to report chest pain or discomfort compared to men. In that study, women's symptoms of an AMI were often "atypical" or different from the classic signs and symptoms noted in men. The study concluded that the inability to recognize symptoms led to delays in receiving timely treatment (Canto et al.).

\section{Symptom Interpretation}

In a qualitative study by McSweeney \& Crane (2000), symptoms women had before and during an AMI were identified. Of the 40 women in the study, 37 experienced prodromal symptoms a few weeks to two years prior to their AMI. The most common symptoms were unusual fatigue, discomfort in the shoulder blade area, and chest sensations. The most frequent acute symptoms were chest sensations, shortness of breath, feeling hot and flushed and unusual fatigue. In a later study, McSweeney et al. (2003) found that of the 515 female patients studied describing prodromal and AMI symptoms, $78 \%$ of women had symptoms for more than a month before their AMI. The most frequent were unusual fatigue $(70.7 \%)$, sleep disturbance $(47.8 \%)$, shortness of breath (42.1\%), indigestion (39.4\%), and anxiety (35.5\%). Only $29.7 \%$ reported prodromal chest discomfort. The most frequent acute symptoms were shortness of breath (57.9\%), weakness $(4.8 \%)$, unusual fatigue $(42.9 \%)$, cold sweats (39\%), back discomfort $(37 \%)$, and chest discomfort $(27.7 \%)$. In their study, $95 \%$ of women experienced prodromal symptoms. Most experienced these symptoms more than one month prior to their cardiac event. Furthermore, $43 \%$ of the women did not have any type of chest discomfort with their AMI (McSweeney et al.). 
In a study of clinical characteristics of patients with AMI, Canto et al. (2000) found that of 434,000 patients, $33 \%$ had no reported chest pain, but were diagnosed with AMI. The study consisted of $49 \%$ women and $38 \%$ men. A correlation was found between lack of chest pain and presence of diabetes. As McSweeny et al. (2003) pointed out: women need to be aware of the range of MI symptoms, so that they can identify and respond to an MI.

Those with diabetes have been found to be at greater risk of delay than those without diabetes. A qualitative description of women interviewed while hospitalized for AMI concluded that women with diabetes may fail to recognize symptoms of AMI and should consider atypical symptoms like unstable blood sugar, shortness of breath, and indigestion as reasons to consult a health care provider (Mayer \& Rosenfield, 2006). According to a presentation by Dr. Barbara Roberts of Miriam Hospital, diabetes has a greater impact on risk in women than in men (Roberts, 2007). Cardiovascular disease is the most common complication of diabetes in women and costs nearly $\$ 3.8$ billion in direct inpatient care in 2001 (Roberts).

Women's Awareness and Perception

Bett, Tonkin, Thompson, \& Aroney (2005) collected data on 1665 patients who presented to 73 hospitals to assess the impact of the Heart Foundation's media campaign to increase public awareness and reduce delay time. The annual heart week campaign included promotion of the message to seek help promptly in television and radio news bulletins, current affairs programs and talk back shows. They advertised on radio, in public transportation, community displays in shopping centers, schools, and sporting 
events. There was a nationwide distribution of leaflets, car stickers, professional papers and posters. The result showed that the median patient delay was not altered by the campaign. The study concluded that a more useful method may be direct education towards high risk patients (known to have CVD, diabetics, elderly) and their families.

An AHA survey demonstrated that $57 \%$ of American women knew that heart disease was their \#1 killer, which indicated an increase of knowledge from 34\% in 2000 and $46 \%$ in 2003 (AHA, 2006). While African and Hispanic women have also demonstrated an increase in awareness, these higher risk groups continue to have lower rates of awareness than white women. Despite the progress made in awareness that heart disease is the number one killer of women, a 2006 survey conducted by Lifetime Television, in conjunction with NHLBI, indicated that many women still do not acknowledge heart disease as their personal risk and most feel that communication is lacking between them and their physicians on the topic (AHA, 2006).

Lack of knowledge, low perception of risk, atypical symptomatology, and increased delay times seeking emergency treatment contribute to women's risk of CVD, indicating a need for direct educational interventions. Since an individuals' perception of personal health threat may be influenced by their attitudes and beliefs, the Health Belief Model (HBM) was the framework chosen to guide the development of this program and is described in the next section. 


\section{Theoretical Frameworks}

\section{The Health Belief Model}

The HBM was one of the first theories of health behavior which extended the use of socio-psychological variables to explain preventive health behavior. It was developed in the 1950's by Hochbaum, Rosenstock, Leventhal and Kegeles, a group of U.S. Public Health Service social psychologists who noticed a widespread failure of people to accept free screening tests for diseases, such as, tuberculosis. The earliest constructs of the model stated that in order for a person to change their behavior to avoid a disease, she would need to believe: (1) that she was personally susceptible to it; (2) that getting the disease would be at least moderately severe; (3) that taking action would be beneficial by lowering susceptibility of the disease or, reducing the severity and; (4) there would be no barriers in adopting such behaviors, such as, increase cost, lack of convenience, pain, or embarrassment (Becker, 1974). The HBM was adapted further by Becker and others in the 1970's and 1980's with the additional constructs of cues to action or the readiness to act and change a behavior and self-efficacy (Glanz, Rimer, \& Lewis, 2002).

The HBM remains one of the most widely recognized health behavioral models in the field. Since health motivation is the main focus of the HBM, it is a good fit for addressing problem behaviors that pose health concerns (e.g., sedentary lifestyle and the risk of heart disease). The six constructs are useful for short and long term behavior change strategies in program planning (Family Health International, 2004). The model is based on the understanding that a person will take health related actions ( i.e., exercise) if that person: feels that a negative health condition can be avoided (heart disease); has a positive 
expectation that by taking a recommended action; she will avoid a negative heart condition (i.e., exercise and diet will help prevent CVD); and believes she can successfully take a recommended health action (i.e., can afford a gym membership, be able to walk in a safe neighborhood, has health insurance) (Glanz et al).

Presently, the six main constructs of the HBM that influence a person's decision to take action to prevent, screen for, and control illness include: (1) perceived susceptibility, ones' belief that they are susceptible to the condition; (2) perceived severity, the belief that the condition has serious consequences; (3) perceived benefits, an individual believes that taking action would reduce their susceptibility to the condition or its severity; (4) perceived barriers, the belief that the costs of taking action are outweighed by the benefits; (5) cue to action, when individuals are prompted to take action from an event, either bodily (physical symptom) or environmental (media publicity) and; (6) selfefficacy, the confidence a person has in their ability to successfully perform an action (Becker, 1974).

The HBM has been applied to study women with heart disease. For instance, Ali (2002) tested a sample of 178 women belonging to three Midwestern churches for several predictors of CVD preventive behaviors derived from the HBM. The study supported the use of HBM variables to design interventions aimed at changing behaviors that increase risk of CVD. The HBM was adapted to this study and included variables for perceptions of susceptibility and seriousness of CVD, socio-psychological variables for general health motivation, and knowledge of risk factors of CHD (Ali). The HBM variables help to address CVD prevention in women. For example, health care workers could use a short 
questionnaire to determine women's perceived or actual risk factors of CHD and tailor the care plan to each woman's beliefs (Ali).

In another study, Callaghan (2005) investigated the relation among health promoting self-care behaviors and self efficacy in older adults by analyzing secondary statistical data. Two significant findings linked income and health insurance with healthy behaviors. Those reporting an adequate income also had higher scores on healthy behaviors, self efficacy, and self care. The second significant finding was that those with a college education also had higher scores for healthy behaviors and ability for self care when compared to those with a high school education. Moreover, those with a support system, married, and having less or no children also reported higher scores in practicing healthy behaviors and having higher self efficacy beliefs.

The HBM may be used as a guide to build messages for health promotion programs (Lennon, 2005). For example, perceived susceptibility refers to a person's belief in the likelihood of getting heart disease and perceived severity is the belief that the disease will result in negative consequences. A perceived benefit involves the individual believing there is value to changing their lifestyle to prevent disease, on the other hand, perceived barriers limit the person's ability to adhere to a health related measure. Self efficacy refers to a person's level of confidence that they can accomplish the measure and the cue to action construct is any message that triggers interest or increases awareness to take action for better health. Cues could be in the form of a poster, a message on the radio or through health education strategies (Lennon). 
An effective health promotion program can have improved outcomes when based on a clear understanding of health behaviors. Conceptual models, such as the HBM, provide a foundation for program planning and development by explaining health behaviors, including processes for changing them and the factors that affect health behaviors (Family Health International, 2004).

Applied to this program development, if individuals lack knowledge about how their behavior puts them at risk for heart disease and they lack susceptibility to disease, then they are not likely to change their behavior to minimize their risk of heart disease. The program planner used the HBM to understand how susceptible the target population felt about heart disease, whether they believed the disease is serious, and if they believed changing their lifestyle could reduce the threat of heart disease at an acceptable cost, and tailored the program accordingly. Knowles' Adult Learning Theory was also used to guide this program development.

\section{Knowles Adult Learning Theory}

The educational interventions developed in this program were grounded in Knowles Adult Learning Theory, introduced as a model of adult education in the 1960's. The underlying principle recognizes that adults have different needs and emphasizes that adult learners are more self-directed and responsible for their decision making. Therefore, adult learning programs and curriculums should accommodate this basic aspect of adult learning for optimal learning outcomes (Knowles Theory of Andragogy, n.d.).

The four main sets of assumptions in the theory are based on the differences between children and adults in terms of self-concept, experience, and readiness of learning, and 
orientation to learning (Knowles, 1969). The assumption of self-concept refers to the mature person moving from a dependent personality toward more self direction. Therefore, adults learn best in situations where there is a mutual relationship with the teacher in terms of learning needs, objectives, planning conduction and evaluation of learning experiences. As the mature person attains lifetime experiences, learning is promoted through methods that use this experience. Thus, there is a shift from lecture and assigned reading to action learning techniques, like projects, case studies, discussions and simulated exercises (Knowles). Under the third assumption, the adults' developmental tasks are concerned with performance in their changing roles of worker, spouse, and parent, which differ from a child's developmental tasks of preparing and becoming (selfidentity). Adults are prepared to learn what is needed by his/her developmental tasks at that time and learn best in a program that coincides with his/her developmental tasks (Knowles). In the last assumption, mature individuals have a different time perspective than youths. Adults learn best when the topic is of immediate value to their job or personal life, whereas, children postpone applications of most learning (Knowles). 


\section{Program Development}

\section{Needs Assessment}

The Community-As-A-Partner Framework (Anderson \& McFarlane, 2008) guided the community needs assessment and the development and evaluation of the proposed plan. Based on Neuman's model of a total-person approach, the model is a combination of public health and nursing. It focuses on four concepts: the person, the environment, health, and nursing (three levels of prevention). The "person" is a population or group of individuals. Everyone in a community represents the person (Anderson \& McFarlane). The "environment" refers to the community and "health" refers to the resources for everyday life. "Nursing" is concerned with the three levels of prevention. Primary prevention goals are aimed at reducing stressors or strengthening the lines of defense. For this educational program, learning about the risk factors of heart disease and how to protect oneself is an example of strengthening the lines of defense. Secondary prevention occurs after a stressor crosses the line of defense (Anderson \& McFarlane). The goal is early detection and treatment. Applied to this program, the students will be encouraged to learn their cholesterol levels for early detection and treatment. Finally, tertiary prevention aims to restore health after a disease is already present. The overarching goal of the model is system equilibrium for a healthy community, including preservation and promotion of community health (Anderson \& McFarlane).

At the core of the assessment wheel are the people of the community. The wheel is comprised of eight subsystems, which helped to guide the needs assessment for this educational program. Given the scope of this project, it was impossible to assess all 
subsystems. Therefore, the health services subsystem was chosen and analyzed as closely as possible, given the time constraints. The community nursing diagnosis was derived after the analysis of the community assessment. The community core was examined by reviewing epidemiologic statistics pertaining specifically to heart disease in Rhode Island women; however, none were found. Identification and support for the educational program was validated by locally obtained information on the needs of people employed at the organization via a discussion group. Local service providers also were interviewed about services as they relate to heart disease, who their clients are and the respondents' opinions of a health promotion program for heart disease. Comments from members of organizations like the American Heart Association and Rhode Island Department of Health were an important component of the needs assessment. The services available to women about heart disease were assessed, as well as the policies needed to be implemented to improve women's knowledge of heart disease and risk perception.

Purpose

The purpose of the needs assessment was to collect and analyze information to better understand the cardiovascular health of the women in Northern RI and to be responsive to the local issues of the women employed at the assisted living community. Another goal of the needs assessment was to look at what educational programs were in place in Rhode Island already. Finally, a discussion group was conducted at the organization to determine what the convenience sample knew about the heart and their health in order to 
develop a better health program for them. The long term goal is to change the policy of the organization to implement an evidence based educational program for staff.

Ethical considerations were made as to whether or not the program raised expectations for changes in which the program director had no intentions of changing. The privacy and comfort of participants was carefully considered throughout the discussion group and program. Another question under consideration was whether or not the topics were relevant to the participants and whether or not the program director's intentions were explicit to participants.

\section{Data Collection}

Information required for the needs assessment included the review of existing data obtained from government sources, the American Heart Association, experts in the field, and the Rhode Island Department of Health regarding the prevalence of heart disease in women and the associated costs. The program director would determine how to incorporate the information obtained into the program or for grant purposes.

National epidemiological data. In the US in 2006, all cardiovascular diseases combined claimed the lives of 432,709 women versus 269,819 women from all forms of cancer combined. In comparison, breast cancer claimed the lives of 40,821 females in 2006. The death rate from CVD was 262.5 per 100,000 ( 215.5 for white females and 298.2 for black females). Twenty three percent of women age 40 and older who have had an initial AMI die within a year compared with $18 \%$ of men, partly because women are older than men when they have their first heart attack (AHA, 2006). Sixty four percent of women who died suddenly of CVD did not have previous symptoms and 704,000 females 
diagnosed with CVD were discharged from short stay hospitalizations in 2006. And, each year, approximately 55,000 more women than men have a stroke due to the fact that average life expectancy for women is greater than it is for men (AHA). Although heart disease is sometimes considered a "man's disease," about the same number of women and men die each year of heart disease in the US. Unfortunately, $36 \%$ of women did not perceive themselves as at risk for heart disease in a 2005 survey (CDC, 2007). Only 55\% of women are aware that heart disease is the leading cause of death among women and just $20 \%$ of women identified heart disease as the greatest health problem facing women today (USDHHS, About the Heart Truth). Furthermore, it is projected that in 2009, heart disease will have cost the US $\$ 304.6$ billion (CDC, 2007).

Vital statistics: Rhode Island. There are 1,069,725 residents living in RI (US Census Bureau, 2006). There are 858,433 whites, 41,922 blacks and 90,820 Hispanics. Of the total, 544,684 are female and 503,635 are male. The median age is 36.7 and 152,402 persons are ages 65 and older. Black and Hispanic populations, live from highest to lowest, in Providence, Pawtucket, Woonsocket and North Providence respectively (Providence County) (Vital Statistics Annual Report, 2000). The South Providence population is comprised mostly of low income, Hispanic and non-Hispanic Black and has a higher age adjusted hospitalization rate for heart disease and stroke than the statewide average (RI Department of Health [RIDOH], 2009). This is significant, since it could mean that racial and ethnic minority groups living in these areas are less likely to receive screening and treatment for risk factors of heart disease and stroke (RIDOH). Unlike the 
National Center for Health Statistics, Rhode Island does not currently have separate statistics for men and women, a limiting factor for this needs assessment.

Mortality/hospitalizations. CVD, which includes heart attack and stroke, is the leading cause of death both nationally and in RI (RIDOH, 2009). In 2007, 27 out of every 10,000 RI residents died from heart disease and 4 out of every 10,000 died from stroke. In the same year, 121 of every 10,000 residents were hospitalized for heart disease and 28 out of every 10,000 were hospitalized for stroke (RIDOH). The average inpatient hospital charges for a primary diagnosis of heart disease and stroke were $\$ 36,202$ and $\$ 28,716$, respectively. In RI, the prevalence of high blood pressure increased from an estimated $25 \%$ in 2001 to $28 \%$ in 2007 . An estimated $33 \%$ of Rhode Islanders reported that they had high cholesterol levels in 2001, which climbed to $38 \%$ in 2007 . Additionally, it is reported that more than $65 \%$ of deaths in diabetes patients are attributed to heart disease and stroke (RIDOH). In 2008, $4.5 \%$ of Rhode Island adults had coronary heart disease, $4 \%$ have had a heart attack, and $2.3 \%$ have had a stroke. In 2005 , the age adjusted mortality rate for CVD in the US was 28.9 per 10,000 and higher in RI, at 38 per 10,000 in the same year. While the mortality rate in RI for CVD deaths declined in 2006 and 2007, RI mortality rates still remain above the national average (RIDOH). According to the CDC, in $2007,7.2 \%$ of Rhode Islanders had diabetes, $17 \%$ were current smokers, $60.8 \%$ were overweight or obese, and $50.1 \%$ reported no exercise in the prior thirty days (CDC, 2007). RI currently does not track the public's knowledge regarding signs and symptoms of a heart attack or stroke. However, beginning in 2009, Behavioral Risk Factor Surveillance System (BRFSS) will include these types of questions (RIDOH, 
2009). Furthermore, other than the data regarding prevalence of CVD among men versus women, no data are available regarding the differences in hospital delay or mortality/morbidity rates between the sexes, even though the literature indicates that women have a higher delay time, higher mortality/morbidity and a low perception of risk to CVD. This is another limitation to the needs assessment and project.

Disparities. Disparities in terms of risk for heart disease and stroke include education, income level, ethnicity, gender, and age. Those persons with less than 12 years of education as compared with greater than 12 years have twice the rate of heart disease and stroke ( $15 \%$ vs. $7 \%)$ and are more likely to have two or more modifiable risk factors (61\% vs. $39 \%)(\mathrm{RIDOH}, 2009)$.

$\mathrm{RI}$ residents with an annual income level less than $\$ 25,000$ have twice the prevalence of heart disease and stroke than adults with higher incomes ( $14 \%$ vs. $6 \%$ respectively). Sixty percent of those in the lower income group have two or more modifiable risk factors when compared to $36 \%$ of those in a higher income group with the same number of risk factors (RIDOH, 2009).

In terms of ethnicity and risk for heart disease or stroke in RI, the data reveal some differences. Non-Hispanic Whites older than age 65 in RI are more likely to die of heart disease than non-Hispanic Blacks and Hispanics in the same age group. Between 2000 and 2007, the age-adjusted hospitalization rate for heart disease and stroke was higher among non-Hispanic Blacks than those of non-Hispanic White or Hispanic descent, possibly a result of lack of access to care or early detection. Non-Hispanic Blacks are also 
more likely to have two or more risk factors for heart disease and stroke when compared to those of non-Hispanic White or Hispanic origins (RIDOH, 2009).

Gender differences reveal that men living in RI have a significantly higher rate of CVD than women ( $9.1 \%$ vs. $7 \%$ respectively). Furthermore, age adjusted hospitalization rates are consistently greater for men than women (RIDOH, 2009).

For RI adults older than 65 years, the prevalence of CVD is six times higher compared to the $18-64$ year old age group ( $24 \%$ vs. $4 \%$ respectively). Adults older than 65 in $\mathrm{RI}$ are more likely to have two or more modifiable risk factors than the $18-64$ group (59\% vs. $35 \%$ ) (RIDOH, 2009). This is significant since RI has 149,775 residents aged $65+$ or $13.9 \%$ of the population, ranking $8^{\text {th }}$ in the nation. Also, RI has 22,707 residents older than 85 years, which represents $2.1 \%$ of the population of older old adults ranking $5^{\text {th }}$ in the nation (US Census Bureau, 2006).

\section{Infrastructure}

$\mathrm{RI}$ is in the early phases of building an infrastructure to reduce the burden of heart disease for its constituents. A state plan has been created and the state presently tracks the burden of heart attack and stroke and is partnering with other agencies to implement prevention activities across the state. Some of the barriers the state faces include; high rates of overweight and obesity, high cholesterol, hypertension, and diabetes; systems of response and care that require improvements; and infrastructure improvements that are needed to improve and track trends in heart disease and stroke. RI currently does not track the public's knowledge regarding signs and symptoms of a heart attack or stroke (RIDOH, 2009). 
The DOH has also developed the HeartSafe community program. It is a program designed to help communities give people a better chance of surviving a heart attack and other cardiac emergencies. For a town to earn certifications, it must meet numerous criteria, such as placing defibrillators throughout the community, offering CPR classes, and creating effective emergency response plans for municipal buildings. On "National Go Red Day of 2010," the DOH announced that Warwick and Westerly had earned the HeartSafe certification (RI.Gov).

\section{CVD Programs}

The RI Department of Health, Chronic Disease Management Division was the first in the nation to launch a Cardiovascular Program that trained and certified nurses, pharmacists and nutritionists as CVD educators. This is an extension of the Certified Diabetic Outpatient Education program. The new CVD program was launched in October of 2009 and successfully trained approximately 40 new educators, who were also certified diabetic outpatient educators (CDOE), a prerequisite for CVD certification. Courses are offered every spring for CDOE certification and in the fall for CVD certification. The CVD training is completed in two full day sessions and covers topics regarding advanced cardiovascular pathophysiology, pharmacotherapeutic management, nutrition, tobacco cessation, and physical activity (D. Goldman, personal communication December 2009).

In 2009, the CDC division for Heart Disease and Stroke Prevention (DHDSP) continued funding in 27 states, including RI for Capacity Building Programs. This program defines the burden of heart disease and stroke, encourages partnerships, and 
develops a comprehensive state plan and pilot interventions (CDC, DHDSP, 2007). Funding was also received to implement a demonstration public health project to improve the management of high blood pressure and high blood cholesterol and improve quality of care in the healthcare setting by enhancing the existing RI Chronic Care Collaboration in nine community based health centers in the state (RIDOH, 2009).

The WISEWOMEN program, also funded by the CDC, provides several interventions to women with low income, under insured or uninsured, and ages 40-64 with chronic diseases. These include risk factor screening, lifestyle intervention, and referral services in an effort to prevent CVD. Nineteen states were funded, excluding RI (CDC, DHDSP, 2007).

According to the USDHHS on Women's Health, the state of RI is the only New England state with an official Office of Women's Health (OWH). The office was established in 1991 to promote health equity for women and girls through gender specific interventions. Their mission is to coordinate internal and external efforts, leverage resources for programs and services, develop policies to support women's health, increase visibility and importance of women's health issues, collaborate with agencies and organizations, and foster and facilitate new practices using multicultural and gender based approaches (USDHHS, OWH). According to K. Bridges (personal communication, February 23,2010 ), team leader of health disparities of the OWH, the Office is "not involved with the planning and implementation of programs, but is more policy oriented." For example, relating to women and heart disease, the Office is currently working with the heart disease and stroke division of the DOH linking the community 
and medical providers. Pilot programs were developed in South Providence to track patients and assure that women in the community are getting the support needed to maintain a healthy lifestyle and to assure follow up after screenings.

\section{Discussion Group/Recruitment}

To achieve the goal of the program and validate the community nursing diagnosis, a discussion group was conducted by this graduate student, who is also the program director. The aim of the meeting was to obtain information about the samples' knowledge and attitude about heart disease and its risk factors. The assisted living organization provided a list of all female employees (including per diems) and every sixth person was selected. An invitation to participate was created by the program director, and after IRB approval, was mailed to the selected individuals describing the program and inviting them to participate in the discussion group (Appendix A). The letter emphasized that their participation would be completely voluntary and that the information would be confidential. Participants could freely choose whether or not to participate and that their decision would not affect their employment in any way. Of the 13 participants selected and invited, 7 chose to attend the discussion group. The participant's were reminded that the discussion would take one hour of their time and that they could withdraw from the discussion group at any time. Three days prior to meeting, each member was called to remind them to attend. The meeting was held in November, 2009 at the assisted living community located in northern Rhode Island. The group was comprised of seven female staff who ranged in age from 25 to 55 years. This was a convenience sample of nursing assistants who all lived in the Providence county area of Rhode Island. 
A series of questions was asked in an informal round table discussion format (Appendix B). The program director took notes of the participants' responses with a pen and a notebook. No tape recording or video surveillance was used. A discussion guide developed by the National Heart, Lung, and Blood Institute (NHLBI) Latino Focus Group Project was used as the agenda. The participants were asked general questions about what they knew about heart disease, prevention, cholesterol, high blood pressure, weight, diet, physical activity and smoking. Questions were asked to identify where participants obtained their health information and what types of information they preferred (brochures, videos, television, etc.). Finally, the group was asked to evaluate the group discussion.

The information from the group discussion revealed lack of knowledge about important risk factors of $\mathrm{CVD}$ and that heart disease is preventable. While the group understood that cholesterol was something bad for their hearts, no one knew their own cholesterol level, or how to lower their levels if they were elevated. The group was also confused about the different types of fats found in foods. While participants were aware that high blood pressure was not good for one's health, stress was the only factor cited as the cause. Contributors such as overweight, poor diet, lack of exercise were not mentioned. Five of seven participants listed something other than heart disease as the greatest risk to their health, which is consistent with the literature. The assisted living staff displayed limited knowledge of heart disease and a lack of perceived threat. The staff had limited access to health promotion activities and was interested in a program at work. The organization lacked a health promotion program and lacked skilled staff to 
provide the education. The discussion group confirmed the need for an educational intervention. The information was used to develop the four sessions of the program. Analysis of Data Derived from the Needs Assessment

CVD is the leading cause of death for Rhode Islander's and mortality rates are above the national average. $\mathrm{RI}$ adults with less than a $12^{\text {th }}$ grade education and an annual income less than 25,000 have almost twice the prevalence of heart disease and stroke than those more educated and in higher income levels. Blacks are more likely to have two or more risk factors of heart disease than Whites or Hispanics and men have a higher rate of CVD and hospital rate than women. Moreover, RI adults aged 65 and older have a higher prevalence of heart disease than those in younger age groups which is significant since Rhode Islanders $65+$ comprise $13.9 \%$ of the population. This has consequences for the state of health care in RI and nationwide since our elderly population is growing. It is projected that by the end of 2050, one out of five Americans will be elderly (US Census, 2006). The RI DOH's innovative CVD program is an excellent step forward in fighting the burden of heart disease in RI. These demographic transitions indicate that more health practitioners will be needed in the future. This represents an opportunity for APNs in the arena of primary care and prevention. Nurses are in an important position to educate and provide health promoting and self management behaviors to decrease and prevent disease, as the elderly will absorb resources and strain budgets. 
Assess Needs and Possible Solution

CVD is a growing problem threatening the health of our nation and the integrity of our health care system. Great strides have been made on national and local levels, but vigorous efforts for awareness need to continue. A CVD educational program could realistically be put into place at the assisted living organization and expanded to the company's four other RI communities, however a change in organizational policy would be required. Although not a simple accomplishment to achieve, it is considered attainable by the program director and is therefore a priority. The majority of employees at the assisted living communities are women, from lower educational and income levels. A workplace program could potentially reach hundreds of women in RI. In addition to reaching staff, residents and their families and surrounding community members could be reached. 


\section{Program Development and Implementation}

\section{Program Goal}

The overall goal of this program was to increase women's knowledge about heart disease and increase their perception of risk. The long term goal is to implement the program in the organization's four assisted living communities in Rhode Island which are located in the towns of Lincoln, East Greenwich, Barrington, and Portsmouth.

\section{Program Overview}

The program was a nurse led, gender specific, educational intervention targeted at women employed in the organization. It took one year to plan, implement, and evaluate the program. The intervention consisted of four educational offerings provided in one hour sessions, held weekly for one month. The sessions were conducted in the evening from 7-8 pm on each Thursday in January. A pre-test was administered prior to the start of each session and a post test was given upon completion of each session to evaluate the effectiveness of the intervention (see Instrument section). A timeline was used to monitor the program activities and to assist in keeping the program on schedule (Appendix C). Program content, goals, and objectives were developed from information obtained from the discussion group, needs assessment and literature review. Each session was developed and delivered by the program director.

\section{Program Resources}

The following resources were needed to plan, implement, and evaluate the program. (1). Personnel needed included a program director, a master's student with 26 years of nursing experience, and staff volunteers to assist in printing, photocopying and 
promoting of the program; (2). Physical resources included a room with tables and chairs, handouts for note taking, pens, paper, a computer with a printer, and a copy machine; (3). Information resources included internet access and professional knowledge; (4). A budget was established for printing costs, postage, envelopes, refreshments, speaker fee. The total projected budget was $\$ 125$, which was donated by the organization.

\section{Setting}

The program took place at an assisted living community located in northern Rhode Island where the program director was employed. Approval was obtained from the organization and from the Rhode Island College Institutional Review Board (IRB).

\section{Sample}

The pilot educational program targeted women ages 18 and older employed at the organization in all departments and their guests. The Licensed Practical Nurse (LPN) staff members were excluded due to their knowledge base. There were no Registered Nurses (RNs) other than the program director employed at the organization. There were a total of 68 women employed at the organization and eligible to participate at the time of the program offering. A total of 17 women ranging in age from 18-65 years responded and participated in either one or two sessions.

\section{Recruitment of Program Participants}

An invitation to participate in the program was created by the director. The invitation described the program and invited potential participants to attend a 4-week health promotion program consisting of four weekly classes for a month (Appendix D). After IRB approval, the invitations were mailed to all female employees four weeks prior to the 
sessions via a mailing list provided by the organization. Participants were instructed that they could bring a guest and were asked to RSVP. In the letter, participants were assured that their participation was voluntary and that their decision to participate or not participate would not affect their work status in any way. While attending all four sessions was encouraged, not attending all sessions was allowed without prejudice.

Notice of the event was also posted on the organization's activity calendar and on a poster that was located in the employee break room. The poster included the topic, location, dates, and times of the sessions. Also, one week prior to the start of the first session, volunteer staff members assisted the program director in promoting the program by distributing flyers in the break room during lunch. The intervention was offered at no cost to the participants and held at the organization which was accessible and convenient for the participants. One barrier was choosing a day and time that was convenient for participants. Those who were scheduled to work on the dates of the sessions were notified that they would be expected to cover the shifts they were scheduled for if they planned to attend the program. The sessions were on employees' personal time and participants were informed that they would not be compensated.

\section{Intervention: Four Educational Sessions}

The content of the educational program was developed by the program director using the literature, clinical experience, and comments obtained from discussion group participants. The program was designed to improve participants' knowledge about heart disease and how they could reduce their risk. Four one hour sessions were designed and topics included: (1) general facts and overview of heart disease; (2) heart disease and risk 
factors; (3) how to promote a healthy lifestyle and; (4) signs and symptoms of a women's heart attack. PowerPoint presentations were developed and used to guide the sessions. Handouts were provided for each of the participants to use as a reference and to take notes if desired.

Knowles Learning Theory of Andragogy helped guide the methods and activities chosen for teaching strategies. Seating was arranged in a circular pattern to promote discussion and a comfortable atmosphere. In addition to using PowerPoint handouts, case studies and role playing were incorporated to more actively engage the learners. Activities, such as having participants calculate their BMI and 10-year risk for developing heart disease using Framingham risk scoring were used to motivate and to provide participants with some relevant information that they could use immediately. The content was tailored to the information obtained from the discussion group (Appendix E). The content was delivered by the program director in a casual and informal manner. Time was reserved for questions and answers at the end of each session.

\section{Pre and Post Test Data Collection Instrument}

The program director collected measurable data using a pre/post test method. Demographic data were also collected and included the participant's age, ethnicity, education level, and occupation. The program director developed pre and post tests derived from the literature and clinical experience. They were administered prior to the start of each session and repeated again immediately following the end of each session. Each of the four weekly tests was comprised of 6-10 questions that were designed to address the objectives of each session. Close-ended questions were constructed so that 
data could be more easily compared and analyzed. Each question had one correct answer and was based on 100 percent. After development of the exams, the author attempted to establish content validity by asking four RNs with several years of clinical experience and expertise to evaluate them. Based on the feedback of those content experts, minor changes were made to the wording of the questions as indicated (Appendix F).

Participants were allowed 15 minutes to complete each test. Since all employees were not be able to attend all four sessions, the pre and post tests were coded so that the program director could match the pre and post tests with the corresponding participant. Participants were asked to pick a password that they could easily remember and enter the password on the top of the tests. The tests were scored and graphed. The number of participants attending was recorded at each session. The group also completed an objective evaluation of each session at its conclusion to give the director feedback about the program delivery, content, and how the intervention could be improved. The evaluation tool used in this program was incorporated from the RI DOH Cardiovascular Outpatient Educator Program, without modification (Appendix G). 


\section{Program Evaluation}

The Community-As-A-Partner Framework (Anderson \& McFarlane, 2008) that guided the community needs assessment, program planning and development was also used to guide program evaluation, using a three-part model. The first part of the model is process evaluation, which answers the question of whether or not the program achieved what it intended. The second part of the model, impact evaluation, measures the immediate impact of the program on the target. Outcome evaluation is concerned with the long term effects of a program, for example impact on mortality or incidence rates.

\section{Process Evaluation}

Process evaluation occurs at the beginning of program implementation and monitors the activities of the program and any changes that develop (i.e., change in location or times of the sessions). The activities in this program were followed according to the time line and the four sessions were successfully delivered, as planned. The program was also well received by participants. Attendees in all four sessions actively engaged in the discussions and in the question and answer portion of the sessions. Participants evaluated each session at its conclusion and the comments for each session were overwhelmingly positive (Appendix H). Participants thought the content was useful, informative, and delivered in a clear and organized manner. Many indicated that they would attend addition sessions like this and would have liked a longer time for the discussions.

One constraint of the program was that the program director was unable to deliver the interventions during working time, which was a preference employees had revealed in the discussion group. The times of the sessions may have contributed to the low attendance 
since staff did not want to leave work, attend the program, and return to work later. Of the 68 employees invited, 25 responded that they would attend, but only 17 attended in total $(25 \%)$. Four of the 17 participants attended two of the sessions, but none attended all four. Participants did not bring guests. All of the participants were resident care assistants from the nursing care department, with no participants from other departments. There was no apparent reason for the drop in attendance other than a conflict with work schedules when sessions were offered. Participants' attendance is depicted in Table 1.

\begin{tabular}{|ll|}
\hline Table 1 & \\
Attendance at Weekly Sessions $\quad(N=17)$ & $\mathrm{n}$ \\
\hline Week and Topic & 8 \\
\hline 1. $\quad$ Heart Disease: A General Overview & 4 \\
2. Heart Disease Risk Factors & 5 \\
3. Heart Disease: How To Protect Yourself & 4 \\
4. Heart Disease: Signs \& Symptoms of a Heart Attack & \\
\hline
\end{tabular}

\section{Impact Evaluation}

Impact evaluation measures the immediate effects of the program on a target group. Since the aim of the program was to improve knowledge about heart disease, pre and post tests were used to measure the change in the groups' knowledge.

Demographic data. The demographics of the participants are illustrated in Table 2. The ages of the women ranged from 21 to 60 years with a mean of 41 years. More than three quarters $(82.4 \%)$ of participants were White and less than one fourth $(17.7 \%)$ were non white. Slightly more than three fourths $(76.5 \%)$ of participants reported a high school diploma compared to only about one fourth $(23.5 \%)$ with some college or a masters 
degree. More than two thirds of participants had income less than $\$ 35.000$ annually. Twenty three percent (23\%) of the participants attended two of the four sessions.

\begin{tabular}{|lcc|}
\hline \multicolumn{3}{|l|}{ Table 2 } \\
Description of Program Sample (N=17) \\
\hline & $\mathrm{n}$ & $\%$ \\
\hline Age (yr) & 3 & $14.3 \%$ \\
$20-30$ & 6 & $28.6 \%$ \\
$31-40$ & 3 & $14.3 \%$ \\
$41-50$ & 5 & $23.8 \%$ \\
$51-60$ & & \\
Race & 14 & $66.7 \%$ \\
White & 2 & $9.5 \%$ \\
African American & 1 & $4.8 \%$ \\
Hispanic & & \\
Educational Level & 13 & $61.9 \%$ \\
High School & 3 & $14.3 \%$ \\
Some College & 1 & $4.8 \%$ \\
College Graduate (4yr) & & \\
Individual Income Level & 1 & $4.8 \%$ \\
No response & 0 & $0.0 \%$ \\
$<25,000$ & 14 & $66.7 \%$ \\
26,000-35,000 & 2 & $9.5 \%$ \\
$36,000-55,000$ & & \\
\hline
\end{tabular}

Knowledge pre and post. Overall pre and post knowledge scores are shown in Table 3. Pre-test scores ranged from $7 \%$ to $75 \%(M=38 \%, S D=18.6 \%)$. The post-tests scores ranged from $40 \%$ to $100 \%(\mathrm{M}=73.4 \%, \mathrm{SD}=19.1 \%)$. The mean score improved dramatically after the intervention ( $38 \%$ pre vs. $73.4 \%$ post). 


\section{Table 3}

Knowledge Before and After the Intervention

\begin{tabular}{|lcccc|}
\hline & $\mathrm{M}$ & $\mathrm{SD}$ & Minimum & Maximum \\
\hline Pre-test & $38.0 \%$ & $18.6 \%$ & $7 \%$ & $75 \%$ \\
& & & & \\
Post-test & $73.4 \%$ & $19.1 \%$ & $40 \%$ & $100 \%$ \\
\hline
\end{tabular}

Knowledge about heart disease improved in $100 \%$ of participants after each session (Figures 1-4). Figure 1 indicates a pre-test score average of $34 \%$ and an average post- test score of $71 \%$. Figure 2 shows the most improvement, with a pre- test average score of $22 \%$ and an average post-test score of $76 \%$. Figure 3 demonstrates an average pre- test score of $49 \%$, increasing to $78 \%$. Figure 4 shows average pre- test scores improved from $22 \%$ to $76 \%$ after the intervention. Participants in sessions 3 and 4 with higher pre- test scores had a smaller improvement on their post test when compared to participants in sessions 1 and 2, who had lower pre test scores and a greater improvement on their post tests. 


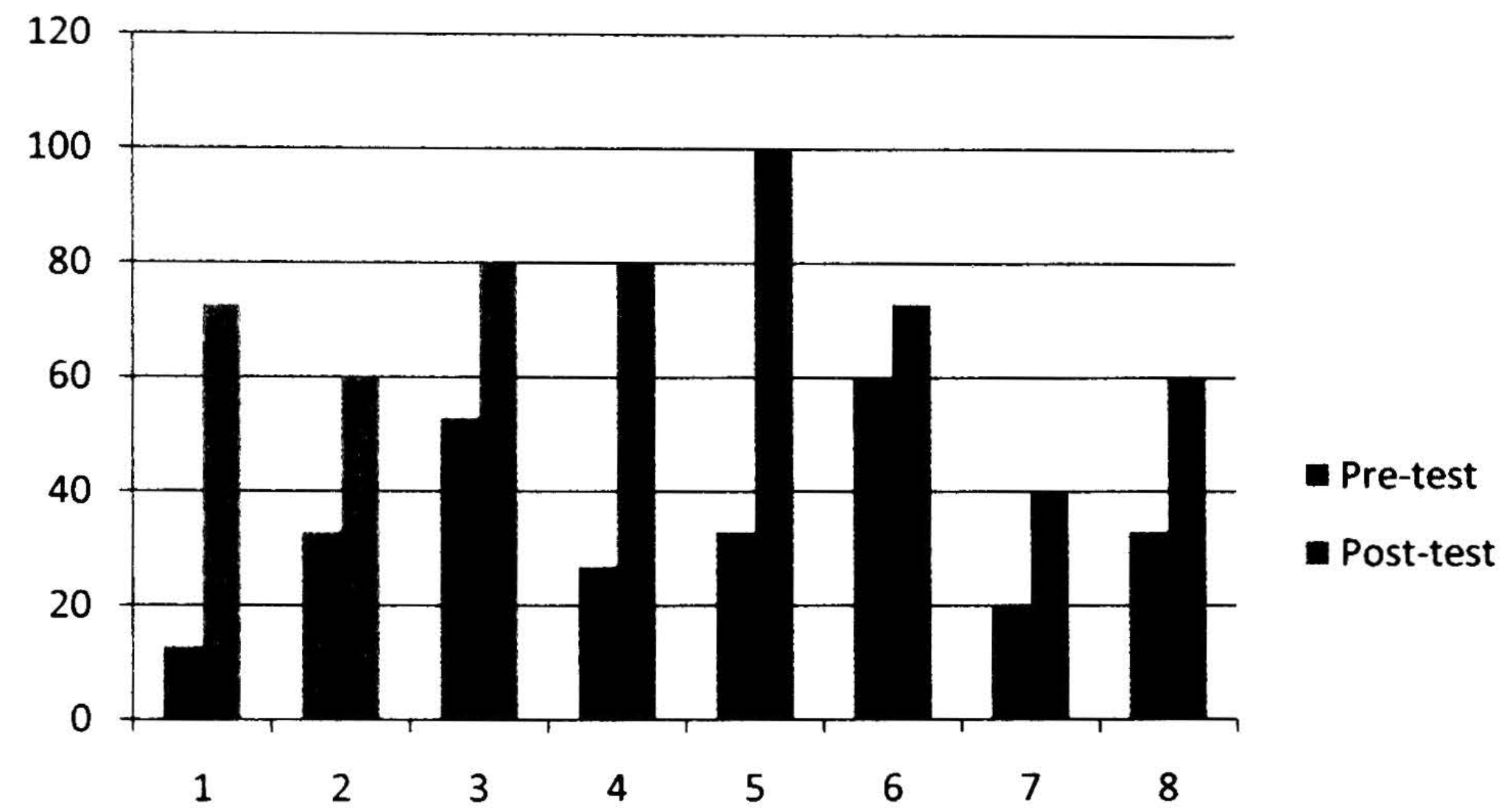

Figure 1. Session \#1: "Heart disease - a general overview. " Pre \& post test results $(n=8)$

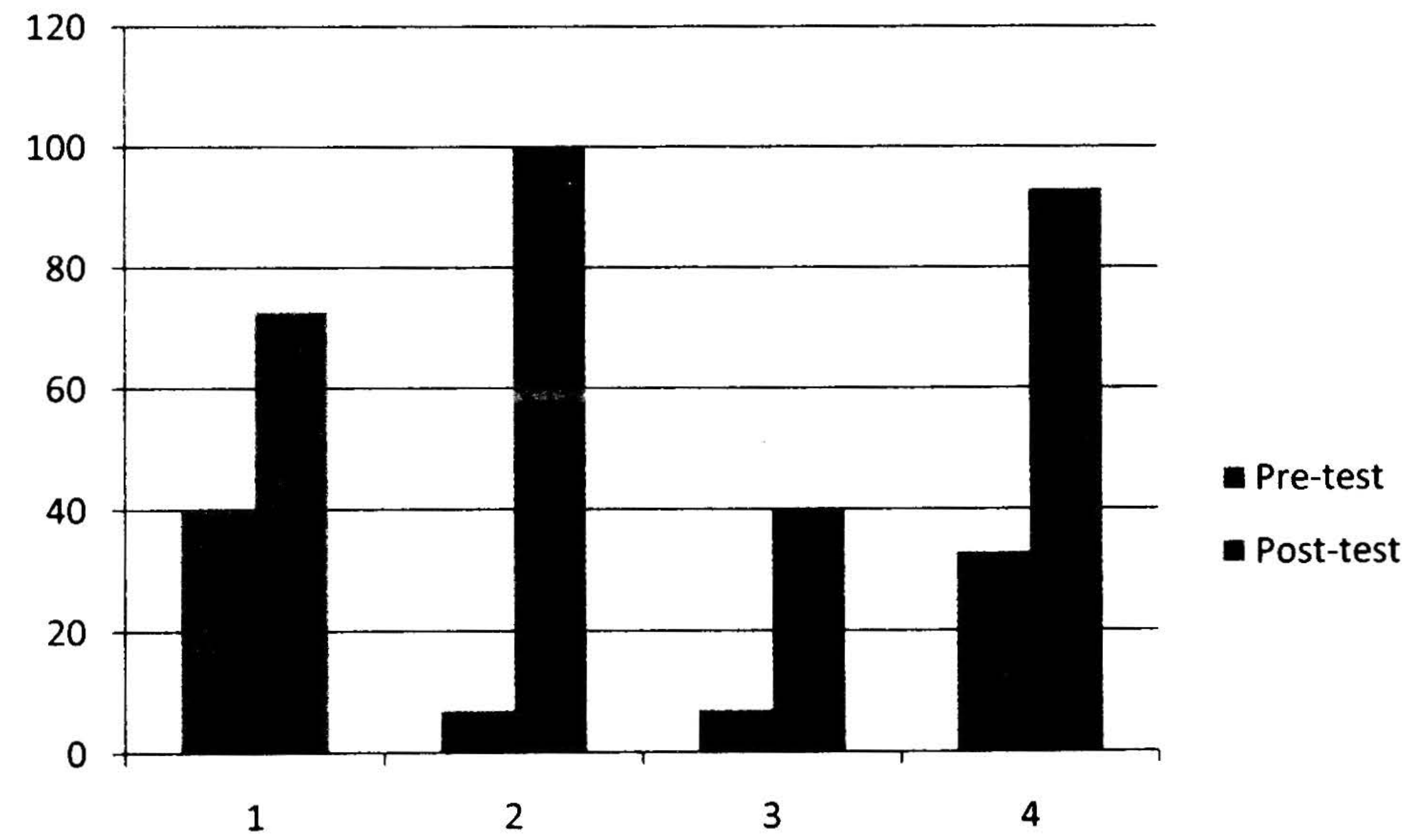

Figure 2. Session \#2: "Heart disease - the risk factors." Pre and post test results $(n=4)$ 


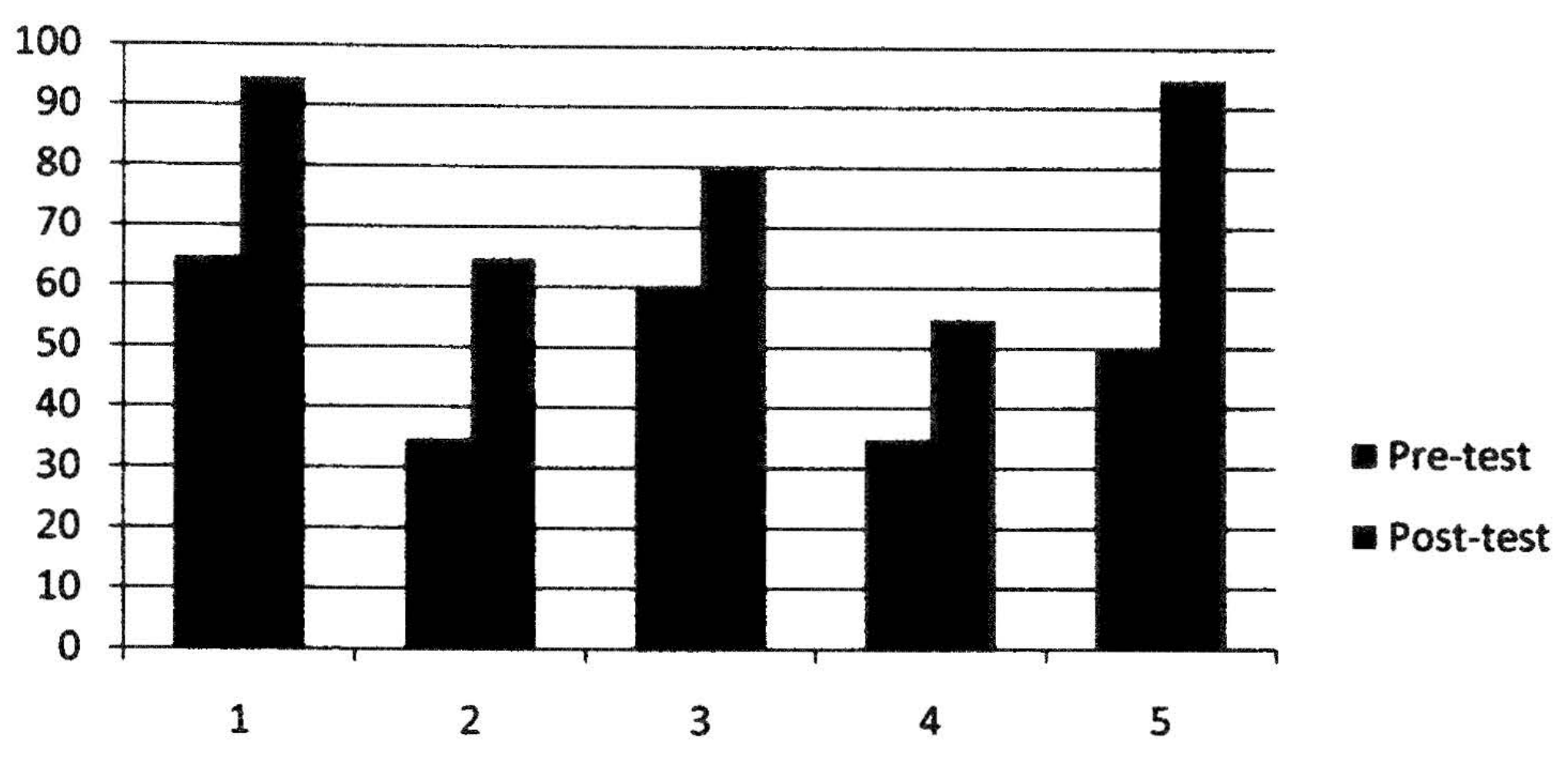

Figure 3. Session \#3: "Heart disease-how to protect yourself." Pre \& post test results $(N=5)$

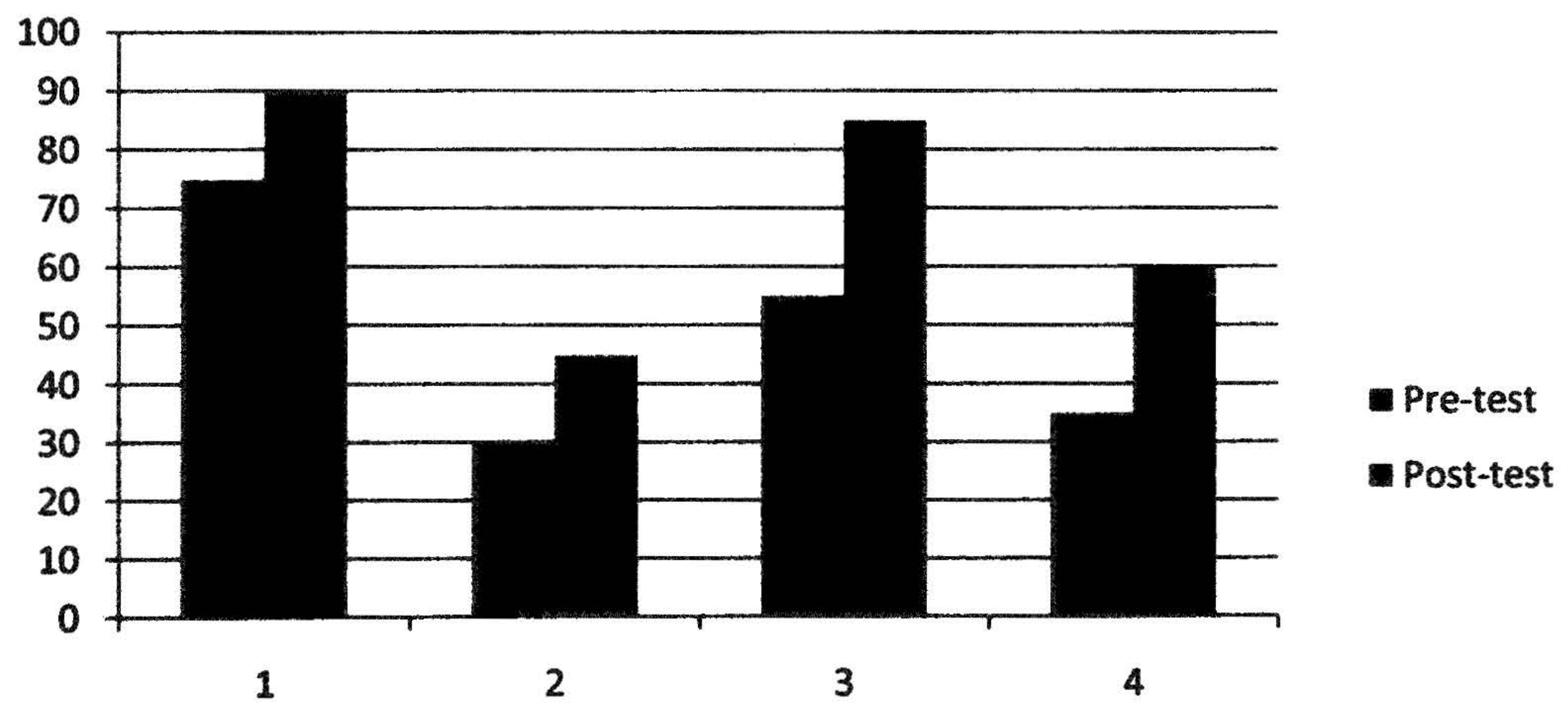

Figure 4. Session \#4: "Heart disease - signs \& symptoms of a heart attack." Pre $\&$ post test results $(n=4)$. 


\section{Outcome Evaluation}

Outcome evaluation measures the long-term effects of a program, such as incidence, prevalence, and mortality rates. For the purposes of this pilot program, only the immediate short term goal was measured, that is, to determine if the program would increase women's knowledge and awareness about heart disease. While participation was less than what was hoped for, the results were notable. The intervention dramatically improved the participants' knowledge in all cases. While the long term goal of the program development (increased knowledge after six months) was not conducted, it would be advantageous to administer a post-test to participants six months after the program to determine retention of knowledge. 


\section{Summary and Conclusions}

Heart disease and stroke are the first and third leading cause of death of American women, respectively. Women from racial/ethnic groups other than white continue to experience a disproportionate burden of these diseases when compared to white women (Lutfiyya, Cumba, McCullough, Barlow, \& Lipshy, 2008). Women continue to delay longer than men in seeking medical attention for an AMI and have higher mortality and morbidity rates (Lefler \& Bondy, 2004). Women's lack of CVD knowledge is validated in national telephone surveys that track awareness, knowledge, and perception of heart disease. While awareness is increasing, many women do not regard heart disease as a major threat to their health and continue to perceive breast cancer as a more likely threat (Thanavaro et al., 2006).

In RI, CVD is the leading cause of death, and the mortality rate for CVD remains above the national average (RIDOH, 2009). Disparities in terms of risk for heart disease and stroke persist for those with low education level, lower socioeconomic status, ethnicity, gender, and age. While RI does not currently monitor the publics' knowledge about heart disease, beginning in 2009, BRFSS will begin to include questions about this type of information (RIDOH). Data is lacking regarding differences between men's and women's mortality and morbidity rates, delay time to hospital, and perception of risk in RI. However, men living in RI have a significantly higher rate of CVD than women, and age adjusted hospitalization rates are also greater (RIDOH).

$\mathrm{RI}$ is responding to the burden of heart disease by building its infrastructure, which is currently in its early phases of development. The state plan includes tracking heart 
disease and stroke statistics and partnering with the community to develop and implement prevention programs across the state (RIDOH, 2009). One of the most significant strides in CVD prevention and management is the CVDOE program, which trains and certifies nurses, dieticians, and pharmacists in the state in order to help educate and empower Rhode Islander's to manage their CVD disease and risks. The state's OWH is another valuable resource promoting health equity for women and girls through gender specific interventions in the state.

While great strides have been made, vigorous public health efforts are needed to raise awareness of the serious consequences of CVD to women's health. Although mass media campaigns have been successful in increasing women's awareness of heart disease as the number one cause of death and illness in the US, the campaigns have not been as successful in changing behavior. Nurse led educational sessions may be more effective in increasing knowledge and perceived risk of heart disease.

The goal of this pilot program was to increase women's knowledge and awareness about heart disease, its risk factors, and personal risk by empowering them with the knowledge to choose healthier lifestyles for themselves and their families. The Health Belief Model, which is focused on health motivation, provided the foundation for the program. In application, if individuals lack knowledge about how their behavior puts them at risk for heart disease and they lack susceptibility of disease, they are not likely to change their behavior to minimize their risk of heart disease. Since the target consisted of adults, methods and activities were grounded in Knowles Adult Learning Theory. For example, role playing and case studies were incorporated into the lessons to actively 
engage the participants. Using activities such as calculating BMI and 10 year risk for heart disease motivated and provided participants with information they could use immediately.

The target was a convenience sample of female staff at an assisted living community in northern RI, where the program director is employed. Licensed Practical nurses were excluded based on the assumption that they already had a knowledge base, and no RNs other than the program director are employed. Thirteen employees were randomly chosen to participate in a discussion group and seven participated. The aim was to determine what the group knew about heart disease, what they were interested in learning about, and what dates and times would be convenient to plan a program. The educational program was developed using their feedback and guided by the literature and the developers' clinical expertise. Four lesson plans were created by the program director and administered weekly for one month as planned. Invitations for the educational program were created and mailed to all 68 female employees. Seventeen employees accepted the invitation and participated in at least one of the four sessions, but not more than two, although attending all four sessions was encouraged. Pre and post tests were used to measure baseline and post program knowledge. Pre-tests revealed that all participants lacked significant information pertaining to heart disease. The majority of participants were White, had no more than a $12^{\text {th }}$ grade education, and had an income level less than $\$ 35,000$ annually. While attendance at the sessions was limited, the results were notable in that this program development demonstrated that small, nurse led interventions can lead to dramatic improvement in knowledge level of participants. 
There were several limitations to this program development project. One of the most significant limitations was that the session dates and times were inconvenient for the target group and may have contributed to the low attendance rate. During the discussion group, attendees revealed that they preferred the times to be immediately following their shifts since they did not want to leave work and then have to return. However, the program director was not able to accommodate their request because it conflicted with the program directors' work schedule. Furthermore, only staff from the nursing department participated. Since the program director is the director of nursing at the assisted living, the nursing staff may have been biased toward participating in the program, though participants were assured that the program was completely voluntary and staff was not coerced in any way to attend. Also, the sample of employees, selected by convenience, represented limited geographical areas of northern RI, thus limiting the generalizability of the findings. Another limitation of this program was instrumentation. The measures were developed by the program developer and were reviewed by nurses who reviewed test questions and answers in an attempt to establish content validity. However, given that this was a program development and not a research study, no further attempts were made to establish reliability and validity.

In conclusion, this nurse developed and led educational program was successful in improving women's knowledge about heart disease and associated risk factors for them as women. Although outside the scope of this project, a long term goal is to re-test participants at three and six months post the educational sessions in order to measure knowledge retention. Organizational policy change to adopt this program is a long range 
goal, with potential for expansion to the organizations' four RI assisted living communities. This expansion could potentially reach hundreds of RI women. 
Recommendations and Implications for Advanced Practice Nursing

\section{Recommendations}

Heart disease kills more women than cancer, chronic lower respiratory diseases, Alzheimer's disease, accidents, and diabetes combined and poses a major public health concern. The financial burden of heart disease is alarming, and as the "baby boom" population enters its peak years, the cost is projected to increase drastically. Moreover, women have a greater life expectancy than men, making them a priority for targeted interventions. The alarming increase in obesity and diabetes also compounds the risk of heart disease for women.

This challenge requires collaborative efforts on the federal, state, and local levels to prevent and manage heart disease and stroke in women. Strong political and economic commitment to nationwide prevention will need to continue. National health promotion efforts targeting women, such as Red Dress Day, have been successful at increasing women's awareness that heart disease is their number killer, but ineffective in improving their perception of risk for the disease. As the Rapid Early Action for Coronary Treatment (REACT) trial demonstrated, educational efforts about risk of AMI symptoms and importance of early treatment failed to decrease delay times. This may indicate that information alone is inadequate and may have little impact on behavior change. It is suggested that research is needed to understand how women perceive vulnerability to risk of heart disease. Funding should be allocated to researching educational interventions that are focused on risk perception and behavior changes in women. 
CVD is a preventable chronic disease. It is recommended that primary interventions focus on youth through health education in schools. The government plays a significant role in preventing heart disease and therefore must continue to commit resources to preventative measures. Examples of legislative changes that encourage healthy habits include the ban on soda and trans-fats in elementary schools, federal food guidelines for participating daycare centers and schools, and the recent no smoking policy initiative. Social structures need to change through political interventions such as taxes on tobacco, policies that promote healthier eating patterns, urban planning, and programs to promote physical activity.

The media also plays a role in heart disease prevention and awareness and can be instrumental in providing health information. It can also have a negative impact. For example, the media helped to create the image of heart disease as a man's disease, much the same as it glamorized cigarette smoking as being "cool" through Joe the Camel and Marlborough Man commercials. A federal mandate, disallowing cigarette commercials on radio and television in the 1960 's, helped to eliminate the negative impact on consumers. Subsequently, the media has been instrumental in portraying cigarette smoking in a negative light. As a result, the US has experienced a declining trend in cigarette smoking. Media could be used in the same way to promote healthy eating habits and exercise. Additional federal mandates could be developed to prevent other commercials that negatively impact the health of our population, and that especially target children. For instance, McDonald's promotes their happy meals by targeting children through give away-toys. Similarly, legislation could ban such commercials. 
Also, in a technological age, the internet, television, and magazines can be a significant tool in reaching large audiences and groups that might be otherwise be inaccessible, through such media as Latino magazines or Spanish speaking television channels.

On a state and local level, the RI DOH has developed a plan for reducing heart disease and stroke burden in RI by 2012. This plan represents a collaborative approach between the DOH and a large, diverse group of community partners. Since heart disease and stroke affect racial and ethnic minority groups and low income groups at higher rates, the plan provides strategies for addressing prevention and management of heart disease in these groups. Additionally, since women in lower income and educational levels without health insurance have an increased risk of CVD morbidity and mortality, targeting this group is suggested as well. Methods to measure outcomes are part of the plan, including BRFSS, hospital discharge data, and vital record data. RI began collecting information regarding signs and symptoms of heart attack and stroke in 2009 , so that data will become available in 2010 . However, it is recommended that gender specific questions about heart disease and women's perceived risk of heart disease be included to help track data on women's knowledge. This will enable that strategies can be incorporated into the plan.

Funds must be devoted to eliminating or reducing disparities in ethnic and racial minority women groups. Treatment of a person as a whole is important for health promotion intervention effectiveness. Social justice is needed to improve inequities. Lack of food options, unsafe neighborhoods, lack of income, and limitations in health care 
access contribute to poor cardiac health. Health promotion strategies that address these barriers and are culturally and linguistically appropriate are crucial.

Since heart disease and stroke are the leading cause of disability in the US workforce, it is recommended that organizations support programs that promote healthy lifestyles, such as smoking cessation, weight loss, and onsite health clubs. Health promotion in the workplace is a unique opportunity to enhance and support the health of an organization's most important asset: its employees. Health education is one strategy to increase knowledge, but whether or not it changes behavior is the question that needs to be answered. Research is needed to focus on methods of behavior change strategies and incorporate them into educational programs and work site policy/wellness programs. Tracking outcomes, such as absenteeism, productivity, retention, and company morale are imperative in monitoring the effectiveness of worksite programs.

The program results revealed that all participants lacked significant information pertaining to heart disease. This is significant given that national campaigns, such as the most recent Red Dress Day have targeted heart disease and women. This might suggest that while mass public educational campaigns are effective in reaching large audiences and educating the public about certain aspects of CVD, they may be less effective in reaching certain groups, especially those of lower socioeconomic and educational status. While promotional pamphlets are numerous regarding heart disease, many are not culturally or linguistically appropriate. Different channels are needed to close the gaps, like nurse led, group tailored sessions to increase the effectiveness of key messages. Alternative methods like storytelling, case scenarios, role playing may be more effective 
for lower literacy and less educated groups. Small group sessions can be tailored to meet this need. With limited public health resources, targeting high risk groups such as ethnic and racial minority women, those with low income and education, known CVD, diabetes, or elderly women may be more efficient. Given the upward trends in chronic diseases and the predicted impact on the health care system in the future, health care professionals who can effectively care for our populations will be tremendously needed. The Advanced Practice Public Health Nurse (APPHN) has the clinical expertise and the academic background to meet these expectations.

Implications for Advanced Practice Nursing

The challenge of preventing and managing heart disease in women will require substantial efforts on a federal, state, and local level. The Advanced Practice Public Health Nurse (APPHN) plays a key role in this challenge. As diabetes, obesity, and life expectancy continue to rise, a competent workforce will be needed to educate and promote the cardiac health of the population. As specialists in community health nursing, APPHNs practice in a variety of settings and are uniquely positioned to have a wide range of influence, making them a key force in meeting this challenge. Their work is based on the core functions of public health: assessment, policy development, and assurance. They are academically prepared to identify community health problems and work to create evidence based interventions. These interventions are designed to improve the health of the community via health promotion program planning, project management, and community partnerships. An essential role of the APPHN is to evaluate 
and measure outcomes to ensure effectiveness of program interventions and to determine the cost benefits of programs so that valuable resources can be efficiently allocated.

APPHNs understand how multiple factors, such as physical environment, genetics, lifestyle behaviors, social support, economic, and educational status influence a populations' health and effect outcomes. Since APPHNs practice in a variety of settings, including government agencies, they have the opportunity to directly or indirectly influence policy and legislature in their role of advocate for their communities. The APPHN understands that statistical data, epidemiological data, and effective health measures are imperative to substantiate and validate policy change. The APPHN supports the equal and fair distribution of health and is an advocate for social justice, a cornerstone of public health nursing. Cultural competency, a core value of public health, is an expectation for APPHNs work, which is important considering the disparities in CVD among ethnic and minority groups.

In the leadership role, APPHNs understand the importance of promoting a competent and diverse workforce so that vulnerable and underserved populations can be assured the necessary health care. They play a key role in assessing program and policy effectiveness and recommending changes as needed to improve the health of communities. With a focus on prevention, the APPHN is significant in identifying and teaching women at highest risk for CVD through empowerment and community involvement.

APPHNs are leaders and community advocates, with high ethical standards and trusted by the public, with a long history of responding to the needs of the community and promoting health. They are health experts who are positioned ubiquitously, so that 
they have a wide range of influence and also are able to witness firsthand the influence of policy on health. APPHNs, therefore, have the opportunity to influence changes in programs and policies to meet the needs of the community. They are change agents, whose clinical expertise and academic preparation in public health make them an essential and key component of our health care system. In the face of limited resources and an upward trend in chronic diseases, APPHNs are a vital asset and resource in the management and prevention of CVD control and health promotion. 


\section{REFERENCES}

Ali, N. (2002). Prediction of coronary heart disease preventive behaviors in women: A test of the health belief model. Women \& Health, 35, 83-96.

American Heart Association (2009). Heart disease and stroke statistics. Retrieved on July 27, 2009 from www.americanheart.org/downloadable/heart/1240250946756LS

American Heart Association (2006). Women and cardiovascular diseases, statistics. Retrieved on January 15, 2010 from www.americanheart.org/downloadable/heart/ 1260905040318 FS10WM10.pdf

Anderson, E. \& McFarlane, J. (2008). Community as partner, theory and practice in nursing, Philadelphia: Lippincott Williams \& Wilkens, p. 295.

Becker, M. (1974). The health belief model and personal health behavior. Thorofare, NJ. pp. 2-8, 21-24

Bett, J., Tonkin, A., Thompson, P., \& Aroney, C. (2005). Current public educational campaigns to impact on the initial response of patients with possible heart attack. Internal Medicine Journal. 35, 279-282.

Brophy, J., Diodati, J., Bogaty, P., \& Theroux, P. (1998). The delay to thrombolysis: An analysis of hospital and patient characteristics. Canadian Medical Association, 158, $475-481$.

Callaghan, D. (2005). Healthy behaviors, self-efficacy, self care, and basic conditioning factors in older adults. Journal of Community Health Nursing. 169-178. 
Canto, J., Goldberg, R., Hand, M., Bonow, R., Sopko, G., Pepine, C., Long, T. (2007). Symptom presentation of women with acute coronary syndromes. Archives of Internal Medicine, 167, Retrieved on June 28, 2009 from http://archinte.amaassn.org/cgi/content/full/167/22/2405

Canto, J., Shlipak, M., Rogers, W., Malmgren, J., Frederick, P., Lambrew, C., Ornato, J., Barron, H., Kiefe, C. (2000). Prevalence, clinical characteristics and mortality among patients with myocardial infarction presenting without chest pain. JAMA, 283, 3223- 3229 .

Centers for Disease Control and Prevention (2008). Addressing the Nation's Leading Killers. Retrieved on October 2, 2008 from www.cdc.gov/nccdphp/publications/ AAG/dhdsp.htm

Centers for Disease Control and Prevention. Division of Heart Disease and Stroke Prevention (2007). State Program: Rhode Island Capacity Building. Retrieved on January 19, 2010 from http://www.cdc.gov/dhdsp/state_program/ri.htm

Christian, A., Mochari, H., \& Mosca, L. (2005). Coronary heart disease in ethnically diverse women: Risk perception and communication. Mayo Clinic Proceedings, 12, 1593-1599.

Christian, A., Rosamond, W., White, A., \& Mosca, L. (2007). Nine-year trends and racial and ethnic disparities in women's awareness of heart disease and stroke: An american heart association national study. Journal of Women's Health,16, 68-80. 
DeLuca. G., Suryapranata, H., Ottervanger, J., \& Antman, E. (2004). Time delay to treatment and mortality in primary angioplasty for acute myocardial infarction. Circulation, 109, 1223-1225.

Family Health International (2004). Behavior change, a summary of four major theories. Retrieved on February 6, 2010 from http://www.fhi.org/en/aids/aidscap/aidspubs/ behres/bcr4theor.html

Finkelstein, E., Khavjou, O., Mobley, L., Haney, D., \& Will, J. (2004). Racial/ethnic disparities in heart disease risk factors among wisewoman enrollees. Journal of Women's Health, 13, 503-515.

Glanz, K., Rimer, B.K., \& Lewis, F.M. (2002). Health behaviors and health education. Theory, Research and Practice. San Francisco: Wiley \& sons. p.52.

Goff, D., Brass, L., Braun, L., Croft, J., Fjlesch, J., Fowkes, J., Hong, Y., Howard, V., Huston, S., Jencks, S., Luepker, R., Maonolio, T., O’Donnell, C., Robertson, R., Rosamond, W., Rumsfeld, J., Sidney, S., Zheng, Z. (2007). Essential features of a surveillance system to support the prevention and management of heart disease and stroke. Circulation, 111, 127-155.

Gurwitz, J., McLaughlin, T., Willison, D., Guadagnoli, E., Hauptman, P., Gao, Soamerai, S. (1997). Delayed hospital presentation in patients who have had acute myocardial infarction. Annals of Internal Medicine, 126, 593-598.

Jacobs, A. \& Eckel, R. (2005). Evaluating and managing cardiovascular disease in women: Understanding a woman's heart. Circulation, 111, 383-384. 
Knowles, M.S. (1969). Higher adult education in the United States. American Council on Education: Washington, DC. p. 29.

Knowles Theory of Andragogy (n.d.). Retrieved on February 6, 2010 from http://tip.psychological.org/ knowles.html

Lefler, L. (2002). The advanced practice nurse's role regarding women's delay in seeking treatment with myocardial infarction. Journal of the American Academy of Nurse Practitioners, 14, 449-455.

Lefler, L. (2004). Perceived risk of heart attack: A function of gender? Nursing Forum, 39, $18-26$.

Lefler, L., \& Bondy, K. (2004). Women's delay in seeking treatment with myocardial infarction: A meta-synthesis. Journal of Cardiovascular Nursing, 19, 251-268.

Leizorovicz, A., Haugh, M., Mercier, C., \& Boissel, J. (1997). Pre-hospital and hospital time delays in thrombolytic treatment in patients with suspected acute myocardial infarction. Analysis of data from the EMIP study. European myocardial infarction project. European Heart Journal, 18, 248-253.

Lennon, J. (2005). The use of the health belief model in dengue health education. Dengue Bulletin, 29, 217-219.

Leslie, W., Urie, A., Hooper, J., \& Morrison, C. (2000). Delay in calling for help during myocardial infarction: Reasons for the delay and subsequent pattern of accessing care. Heart, 84, 137-141. 
Lutfiyya, M., Cumba, M., McCullough, J., Barlow, E., \& Lipsky, M. (2008). Disparities in adult african american women's knowledge of heart attack and stroke symptomatology: An analysis of 2003-2005 behavioral risk factor surveillance survey data. Journal of Woman's Health, 17, 805-812.

Mayer, D., \& Rosenfield, A. (2006). Symptom Interpretation in women with diabetes and myocardial infarction. A qualitative study. The Diabetic Educator, 32, 918-924.

McDonald, D., Goncalves, P., Almario, V., Krafewski, A., Cervera, P., Kaeser, D., Lillvik, C., Sajkowicz, T., Moose, P. (2006). Assisting women to learn myocardial infarction symptoms. Public Health Nursing, 23, 216-223.

McSweeney, J., \& Crane, P. (2000). Challenging the rules: Women's prodromal and acute symptoms of myocardial infarction. Research in Nursing \& Health, 23, 135-146.

McSweeney, J., Cody, M., Sullivan, P., Elberson, K., Moser, D., \& Garvin, B. (2003). Women's early warning symptoms of acute myocardial infarction. Circulation, 108, 2619-2623.

National Heart Lung Blood Institute. Latino Community CVD Preventative Outreach Initiative. Retrieved on September 22, 2009 from www.nhlbi.nih.gov/health/prof/ heart/latino/focusgrp.pdf

Rhode Island Department of Health (2009). Heart Disease \& Stroke Prevention Program: The Rhode Island State Plan. Retrieved on January 15, 2010 from www.health.ri.gov 
RI.Gov: Rhode Island Government Online. Two RI communities awarded heartsafe certification. Retrieved on February 20, 2010 from http://www.rigov/press/view/ php?id=10696

Roberts, B., MD. (2007). Gender specific aspects of cardiovascular disease. (A Presentation, at Miriam Hospital).

Thanavaro, J., Moore, S., Anthony, M., Narsavage, G., Delicath, T. (2006). Predictors of poor coronary heart disease knowledge levels in women without prior coronary heart disease. Journal of the American Academy of Nurse Practitioner, 18, 574-581.

US Census Bureau, 2006. Rhode Island's Senior Population By the Numbers. Retrieved on February 6, 2010 from http://www.dea.ri.gov/stats/

US Department of Health and Human Services. Office of Women's Health. Regional offices and programs. Retrieved on January 17, 2010 from http://www.womens health.gov/owh/reg/1/

US Department of Health and Human Services. National Heart, Lung, \& Blood Institute. About the heart truth. Retrieved on July 27, 2009 from www.nhlbi.nih.gov// educational/ hearttruth/about/index.htm

Vital Statistics Annual Report, (2000). Division of vital records from the rhode island department of Health. Retrieved on January 19, 2010 from www.health.ri.gov/chic/ vital/report.php 
A Gender Specific Educational 59

Appendix A

Invitation for Discussion Group 
Dear Staff Member:

I am an employee at Atria and a graduate nursing student at Rhode Island College developing a health promotion program about heart disease. I would like to invite you to participate in a focus group so that I can learn more about what you think is important to you about heart disease.

Your participation in this focus group is completely voluntary. Your decision to participate or not to participate does not affect your employment at Atria in any way. You may at any time choose not to participate.

The focus group would take one hour of your time. It will be held in the fitness room at Atria. It will be an informal meeting of about 5-10 other Atria employees. There will be no tests. The group will be asked questions, like, "What do you know about heart disease." There are no questions that should cause you discomfort. You may choose at any time not to participate.

Your participation in the focus group may not benefit you personally. I am hoping that information from the focus group discussions will help me know what areas about heart disease you want to learn about.

The discussions in the focus group will not be tape recorded, but I will take notes to help me remember what I learn. All information obtained will be kept confidential. None of the information will have your name or any number to identify you personally. To volunteer to participate in the focus, call me at (401)273-9188. A date and time to meet for the focus group will be discussed at that time. With your permission, I will contact you before the group meets to remind you of the date and time and to determine if you are still interested in participating.

If you have any questions about the focus group or the health promotion program itself, please feel free to call me at the number mentioned above.

If you have any questions or complaints about your rights as a participant in this program, feel free to contact the Chair of the Institutional Review Board at Rhode Island College by sending an email to IRB@ric.edu, by calling 401-456-8228, or by writing to: Chair of the IRB, c/o Office of Research and Grants Administration, Rhode Island College, 600 Mount Pleasant Avenue, Providence, RI, 20908.

Sincerely,

Debra L. Campo, RN, MBA

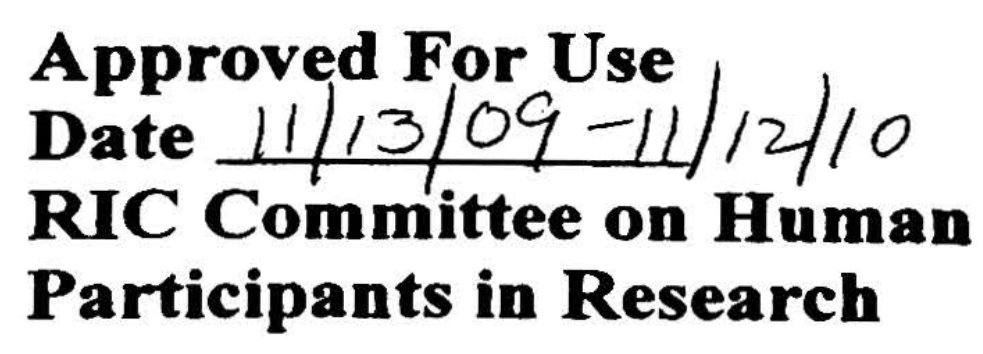


A Gender Specific Educational 61

Appendix B

Discussion Group Questions 


\section{Discussion Group Questions}

\section{A. Heart Disease}

1. What do you know about heart disease?

2. What are different words you have heard that describe heart disease?

3. Who do you think is most likely to get heart disease? Why?

4. Have you heard the term "risk factors?" If so, what does it mean to you?

\section{B. Prevention}

1. What does prevention mean to you?

2. Do you think that heart disease can be prevented? Why or why not?

\section{Cholesterol}

1. Who has heard the word cholesterol and what does it mean to you?

2. Where is cholesterol found?

3. Who is most likely to have high blood cholesterol? Why?

4. Have you heard about saturated fat? What have you heard?

5. What can you do to find out your cholesterol level? What is a desirable or a healthy level? What is too high? Do you know your level? If a person has high blood cholesterol, should she be concerned? Why or why not?

6. If a person wants to have a healthy cholesterol level, what should they do? 


\section{D. $\quad$ High Blood Pressure}

1. What have you heard about high blood pressure?

2. What are other words that are used to describe high blood pressure?

3. Who do you think is most likely to get high blood pressure?

4. Why do you think people get high blood pressure?

5. How does a person know if they have high blood pressure?

6. What is considered a normal blood pressure level? What is high?

7. Should people with high blood pressure be concerned about it? Why or why not?

8. What can a person do to have a normal blood pressure?

9. If you were asked to eat less salt, what would you do? Would it be easy or difficult?

10. Do you think that drinking alcohol affects the heart? How?

E. Weight

1. Do you think that your weight influences your health? How?

2. Why do you think people gain weight?

3. Tell me what you have heard or what you know about calories.

4. If you want to lose weight, what would you do?

F. Diet

1. What foods do you eat that are healthy? How often do you eat fruits and vegetables?

2. Do you ever eat out? If yes, where do you go? How often do you eat out? 
G. Physical Activity

1. What does physical activity mean to you?

2. What have you heard about exercise and heart disease?

3. Do you exercise? If yes, what do you do? How often and how much time?

4. For those of you who do not exercise, why don't you?

H. Smoking

1. What have you heard about smoking?

2. How does someone else's smoke affect those around them?

3. If you do not want people to smoke in your house, what would you say to Them?

I. Health Information

1. Where do you get information about health?

2. What kinds of health information would be most helpful to you? 
Appendix C

Program Timeline 
Program Timeline

\begin{tabular}{|c|c|c|c|c|c|c|c|c|c|c|c|c|}
\hline Activity: & June & July & Aug & Sept & Oct & Nov & Dec & Jan & Feb & Mar & Apr & May \\
\hline $\begin{array}{l}\text { Planning } \\
\text { group } \\
\text { convenes }\end{array}$ & $\mathrm{X}$ & & & & & & & & & & & \\
\hline $\begin{array}{l}\text { Needs } \\
\text { assessment }\end{array}$ & & & $X$ & & & & & & & & & \\
\hline $\begin{array}{l}\text { Problem } \\
\text { statement/obj }\end{array}$ & & & $X$ & & & & & & & & & \\
\hline $\begin{array}{l}\text { Program } \\
\text { theory }\end{array}$ & & & $\mathrm{X}$ & & & & & & & & & \\
\hline $\begin{array}{l}\text { RIC IRB } \\
\text { approval }\end{array}$ & & & & & & $\mathrm{X}$ & & & & & & \\
\hline $\begin{array}{l}\text { Social } \\
\text { marketing }\end{array}$ & & & & & & & $\mathrm{X}$ & & & & & \\
\hline $\begin{array}{l}\text { Deliver } \\
\text { program }\end{array}$ & & & & & & & & $\mathrm{X}$ & & & & \\
\hline $\begin{array}{l}\text { Process } \\
\text { evaluation }\end{array}$ & & & & & & & & $\mathrm{X}$ & & & & \\
\hline $\begin{array}{l}\text { Outcome } \\
\text { evaluation }\end{array}$ & & & & & & & $\mathrm{X}$ & $\mathrm{X}$ & & & & \\
\hline $\begin{array}{l}\text { Analyze } \\
\text { evaluation } \\
\text { data }\end{array}$ & & & & & & & & & $\mathrm{X}$ & & & \\
\hline $\begin{array}{l}\text { Produce } \\
\text { reports }\end{array}$ & & & & & & & & & & $\mathrm{X}$ & & \\
\hline Disseminate & & & & & & & & & & & & $\mathrm{X}$ \\
\hline
\end{tabular}


A Gender Specific Educational 67

Appendix D

Invitation to the Program 
Dear Staff Member,

I am an employee of Atria and a graduate nursing student at Rhode Island College. As part of my requirements for school, I have developed a health promotion program for women about heart disease.

I would like to extend an invitation to you and a guest to attend this educational series about heart disease and women. Four one-hour sessions have been developed and will be offered once a week for four weeks. The sessions will take place in the fitness center at Atria on the following dates and times:

Each session would take 60 minutes of your time. Attending these sessions is completely optional .Your attending or not attending will in no way affect your employment at Atria. While you are encouraged to attend all sessions, attendance at all sessions is not mandatory.

A short multiple choice test, of no more than 20 questions would be given prior to the start of each session. You would be asked to write a password on the top of each test that you could easily remember. After all the sessions were completed, another test of no more than 20 multiple choice questions would be given to test what you learned. The password that you choose would also be written on this test.

None of the tests would have your name or any number on it that would identify you personally. The tests would each take about 15 minutes of your time. Your completion of the tests are completely voluntary and may not benefit you personally. The tests are the only thing we will ask of you. There are no questions that should cause you any discomfort. If you do not want to complete the tests, you are free to choose not to. The tests and any other information obtained during the sessions will be kept confidential. You are free to choose not to participate at any time.

If you have any questions about the tests or this education program, please feel free to call me at 401-273-9188.

If you have any questions or complaints about your rights as a participant in this project please feel free to contact the Chair of the Institutional Review Board at Rhode Island College by sending an email to IRB@ric.edu, by phoning 401-456-8228, or by writing to Chair of the IRB, c/o Office of Research and Grants Administration, Rhode Island College, 600 Mount Pleasant Avenue, Providence, RI 02908.

Please RSVP by at (401) 273-9188. With your permission, I will contact you before the sessions to remind you of the date and time and to determine if you are still interested in participating. Thank you very much for your time and consideration.

Sincerely,

Debra L. Campo, RN, MBA

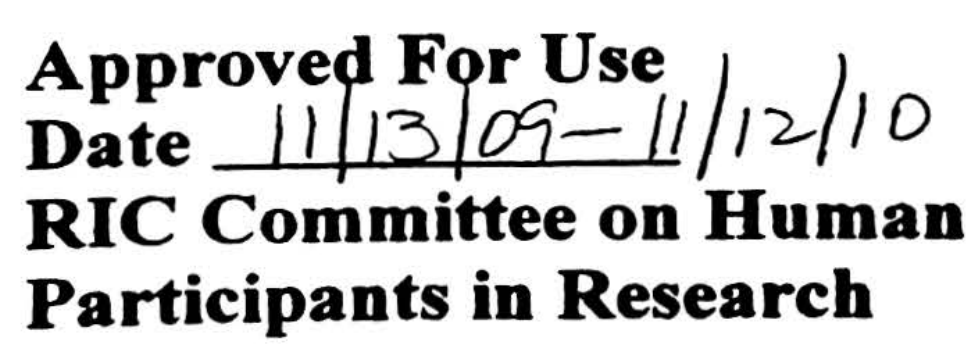


Appendix E

Lesson Plans Blueprints for Sessions 1-4 
Lesson Plans Blueprints for Sessions 1-4

Lesson 1 Blueprint

Topic: Heart Disease: A General Overview

Goal: Understand General Facts about Heart Disease

\begin{tabular}{|c|c|c|c|}
\hline Objectives & Content Outline & Methods \& Activities & Suggested Resources \\
\hline $\begin{array}{l}\text { 1. Given the end of } \\
\text { class, define heart } \\
\text { disease(HD) } \\
\text { in one or two } \\
\text { sentences correctly }\end{array}$ & $\begin{array}{l}\mathrm{HD} \text { is a broad } \\
\text { term, includes } \\
\text { other conditions } \\
\mathrm{HD} \text { is any } \\
\text { diseases of the } \\
\text { heart or blood } \\
\text { vessels } \\
>\quad \text { Distinguish } \\
\text { between HD \& } \\
\text { CHD } \\
\text { A preventable } \\
\text { chronic disease }\end{array}$ & $\begin{array}{l}>\text { Lecture } \\
>\text { Discussion } \\
>\text { Questioning }\end{array}$ & $\begin{array}{ll}> & \text { Handout-About } \\
& \text { Heart Disease } \\
>\quad \text { Internet Resources: } \\
\text {-www.cdc.gov } \\
\text {-www.americanhear }\end{array}$ \\
\hline $\begin{array}{l}\text { 2. Given the end of } \\
\text { class, accurately } \\
\text { explain the most } \\
\text { common form of HD }\end{array}$ & $\begin{array}{l}\text { CHD is most the } \\
\text { common type of } \\
\text { HD } \\
\text { What is } \\
\text { atherosclerosis? } \\
\text { Risk factors for } \\
\text { CAD: blood } \\
\text { pressure, } \\
\text { cholesterol, } \\
\text { cigarettes, } \\
\text { diabetes } \\
\text { How risk factors } \\
\text { cause CAD }\end{array}$ & $\begin{array}{l}>\text { Lecture } \\
>\text { Discussion } \\
>\text { Questioning }\end{array}$ & $\begin{array}{l}\text { Handout- } \\
\text { Atherosclerosis, How } \\
\text { to Keep a Silent Killer } \\
\text { at Bay }\end{array}$ \\
\hline $\begin{array}{l}\text { 3. Given a handout } \\
\text { explain how CHD leads } \\
\text { to a heart attack }\end{array}$ & $\begin{array}{l}>\quad \text { How CHD can } \\
\text { lead to heart } \\
\text { attack } \\
>\quad \begin{array}{l}\text { Narrowing of } \\
\text { arteries }\end{array} \\
>\quad \text { What is angina }\end{array}$ & $\begin{aligned}> & \mathrm{A} / \mathrm{V} \\
& \text { presentation } \\
> & \text { Discussion } \\
> & \text { Questioning }\end{aligned}$ & $\begin{array}{l}\quad \text { Movie-CAD Overview } \\
\text { http://www.youtube.com/ } \\
\text { watch/v=SjRPxGNOT\&feature } \\
=\text { related }\end{array}$ \\
\hline & & & \\
\hline
\end{tabular}




\section{Lesson 2 Blueprint}

Topic: The Risk Factors Associated with Heart Disease

Goal: Know the Risk Factors

\begin{tabular}{|c|c|c|c|}
\hline Objectives & Content Outline & Methods \& Activities & Suggested Resources \\
\hline $\begin{array}{l}\text { 1. Given the end } \\
\text { of class, list } 3-5 \\
\text { major risk factors } \\
\text { correctly }\end{array}$ & $\begin{array}{l}\text { Define risk } \\
\text { factors } \\
\text { More you have, } \\
\text { the greater the } \\
\text { risk } \\
\text { Most risk } \\
\text { factors can be } \\
\text { modified } \\
\text { Important to } \\
\text { take steps to } \\
\text { decrease risk } \\
\text { factors }\end{array}$ & $\begin{array}{ll}> & \text { Lecture } \\
> & \text { Discussion } \\
> & \text { Activities }\end{array}$ & 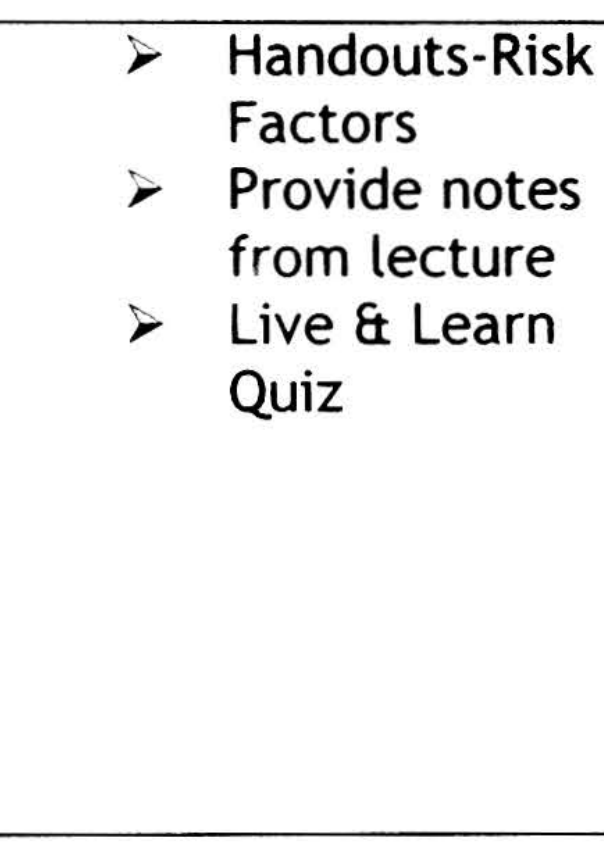 \\
\hline $\begin{array}{l}\text { 2. Given a handout } \\
\text { on major or } \\
\text { contributing risk } \\
\text { factors, correctly } \\
\text { state which group } \\
\text { to place risk } \\
\text { factors }\end{array}$ & $\begin{array}{l}\text { Discuss } \\
\text { controllable } \\
\text { risk factors: } \\
\text { hypertension, } \\
\text { cholesterol, } \\
\text { smoking, } \\
\text { diabetes, } \\
\text { overweight, } \\
\text { inactivity } \\
\text { Discuss } \\
\text { uncontrollable } \\
\text { risk factors: } \\
\text { age, family } \\
\text { history }\end{array}$ & $\begin{array}{l}>\text { Lecture } \\
>\text { Discussion } \\
>\text { Exercises }\end{array}$ & $\begin{aligned} &> \text { Handout- } \\
& \text { Coronary Risk } \text { Factors } \\
& \text { Provide notes } \\
& \text { from lecture } \\
&> \text { Matching } \\
& \text { exercise }\end{aligned}$ \\
\hline $\begin{array}{l}\text { 3. Given a risk } \\
\text { assessment } \\
\text { handout, } \\
\text { determine their } \\
\text { own personal risk } \\
\text { for HD }\end{array}$ & $\begin{array}{l}\text { Review risk } \\
\text { assessment } \\
\text { tool } \\
\text { Discuss BMI as } \\
\text { reliable } \\
\text { indicator of } \\
\text { body fat } \\
\text { Remind tool } \\
\text { does not } \\
\text { replace advice } \\
\text { of physician }\end{array}$ & $\begin{array}{l}>\text { Discussion } \\
>\text { Activity } \\
>\text { Exercises }\end{array}$ & $\begin{array}{c}\quad \text { Handout-Risk } \\
\text { Assessment } \\
\quad \text { Internet } \\
\text { Resource: } \\
\text { www.cdc.gov } \\
\text { www.nhlbi.nih.gov }\end{array}$ \\
\hline 4. Given the end & Definition of & $>$ Lecture & $>$ Handout- \\
\hline
\end{tabular}




\begin{tabular}{|c|c|c|c|}
\hline $\begin{array}{l}\text { of class, discuss in } \\
3-4 \text { sentences, the } \\
\text { impact of diabetes } \\
\text { on } \mathrm{HD}\end{array}$ & $\begin{array}{l}\text { metabolic } \\
\text { syndrome } \\
\text { The } \\
\text { relationship of } \\
\text { physical } \\
\text { inactivity and } \\
\text { excess body } \\
\text { fat \& diabetes }\end{array}$ & $\begin{array}{l}>\text { Discussion } \\
>\text { Project }\end{array}$ & $\begin{array}{l}\text { Metabolic Syndrome: } \\
\text { Another Reason to Stay } \\
\text { on Track } \\
\text { D Handout- } \\
\text { Diabetes \& Heart } \\
\text { Disease }\end{array}$ \\
\hline $\begin{array}{l}\text { 5. By end of class, } \\
\text { compute personal } \\
\text { body mass index, } \\
\text { using BMI chart }\end{array}$ & $\begin{array}{l}\text { BMI is a } \\
\text { reliable } \\
\text { indicator of } \\
\text { body fat } \\
\text { Body fat is } \\
\text { related to risk } \\
\text { of disease } \\
\text { Discuss limits }\end{array}$ & $\begin{array}{ll}> & \text { Discussion } \\
> & \text { Activity } \\
> & \text { Lecture }\end{array}$ & $\begin{aligned}> & \text { Handout-BMI } \\
& \text { chart } \\
> & \text { Handout-What } \\
& \text { Is Fat }\end{aligned}$ \\
\hline
\end{tabular}

Lesson 3 Blueprint

Topic: How to Protect Yourself from Heart Disease

Goal: Know how to promote and maintain a healthy lifestyle

\begin{tabular}{|c|c|c|c|}
\hline Objectives & Content Outline & Methods \& Activities & Suggested Resources \\
\hline $\begin{array}{l}\text { 1. At the end } \\
\text { of class, } \\
\text { identify } 3 \\
\text { ways to lower } \\
\text { risk of HD }\end{array}$ & $\begin{array}{l}>\text { Increase } \\
\text { exercise } \\
=\text { Avoid high fat } \\
\text { diet } \\
=\text { Healthy weight } \\
\text { \& cholesterol } \\
>\text { Don't smoke } \\
>\text { Stress \& } \\
\text { alcohol }\end{array}$ & $\begin{array}{l}>\text { Lecture } \\
>\text { Discussion } \\
>\text { Activities }\end{array}$ & $\begin{array}{l}>\text { Handout-Guide to Physical } \\
\text { Activity } \\
>\text { Handout-Cholesterol Quiz } \\
>\text { Internet Resources- } \\
\text { www.pbs.org } \\
\text {-www.americanheart.or }\end{array}$ \\
\hline $\begin{array}{l}\text { 2. Given the } \\
\text { internet } \\
\text { resources, } \\
\text { design } \\
\text { personal diet } \\
\text { plan }\end{array}$ & $\begin{array}{l}\text { What is fat } \\
\text { Bad fat vs. } \\
\text { good fat } \\
\text { Saturated, } \\
\text { Unsaturated, } \\
\text { Transfat, \& } \\
\text { Total fat }\end{array}$ & $\begin{array}{l}>\text { Discussion } \\
>\text { Questioning } \\
>\text { Projects }\end{array}$ & $\begin{array}{l}>\text { Handout-TLC diet } \\
>\quad \text { Internet Resources- } \\
\text { www.mypyramidtracker.g } \\
\text { ov } \\
>\quad \text { Handout-Healthy Heart } \\
\text { Plan } \\
>\text { Handout- Follow a healthy } \\
\text { eating plan }\end{array}$ \\
\hline & & & \\
\hline
\end{tabular}




\begin{tabular}{|c|c|c|c|c|c|}
\hline $\begin{array}{l}\text { 3. Given a } \\
\text { handout, } \\
\text { accurately } \\
\text { examine food } \\
\text { labels }\end{array}$ & & $\begin{array}{l}\text { How to } \\
\text { understand \& } \\
\text { use nutrition } \\
\text { facts label }\end{array}$ & $\begin{array}{l}>\text { Project } \\
>\text { Discussion } \\
>\text { Exercises }\end{array}$ & $>$ & $\begin{array}{l}\text { Handouts-How to } \\
\text { understand \& use } \\
\text { nutritional facts label } \\
\text {-www.cfsan.fda.gov }\end{array}$ \\
\hline $\begin{array}{l}\text { 4. By the end } \\
\text { of class, } \\
\text { discuss the } \\
\text { role of diet \& } \\
\text { exercise in } \\
\text { preventing } \\
\text { HD }\end{array}$ & $>$ & $\begin{array}{l}\text { Physical } \\
\text { activity \& role } \\
\text { in controlling } \\
\text { cholesterol } \\
\text { and blood } \\
\text { pressure } \\
\text { How to get } \\
\text { active } \\
\text { The role of diet } \\
\text { in reducing } \\
\text { cholesterol \& } \\
\text { blood pressure }\end{array}$ & $\begin{array}{l}>\text { Guest } \\
>\text { Discussion } \\
>\text { Questioning }\end{array}$ & $>$ & $\begin{array}{l}\text { Handouts-Understanding } \\
\text { blood pressure } \\
\text { Registered Nurse-guest } \\
\text { speaker }\end{array}$ \\
\hline
\end{tabular}

Lesson 4 Blueprint

Topic: Women \& Heart Attack-Know the Differences

Goal: Know the differences between women and men

\begin{tabular}{|c|c|c|c|}
\hline Objective & Content Outline & Methods \& Activities & Suggested Resources \\
\hline $\begin{array}{l}\text { 1. By the end } \\
\text { of class, list } 3 \\
\text { most common s } \\
\& \text { s of a heart } \\
\text { attack and } 3 \\
\text { uncommon } \\
\text { correctly }\end{array}$ & $\begin{aligned} &> \text { Typical Signs } \\
& \text { and symptoms }\end{aligned}$ & $\begin{array}{l}>\text { Lecture } \\
>\text { Discussion } \\
>\text { Activities }\end{array}$ & $\begin{array}{l}\text { Handouts- } \\
\text { Heart attack, } \\
\text { stroke \& } \\
\text { cardiac arrest }\end{array}$ \\
\hline $\begin{array}{l}\text { 2. Given a case } \\
\text { scenario of a } \\
\text { female having } \\
\text { uncommon s } \\
\& s \text {, } \\
\text { demonstrate } \\
\text { early } \\
\text { identification } \\
\text { and correct } \\
\text { steps of what } \\
\text { to do }\end{array}$ & $\begin{array}{l}\text { Why it is } \\
\text { important to } \\
\text { identify } \\
\text { symptoms as } \\
\text { cardiac \& act } \\
\text { quickly } \\
>\text { Discuss } \\
\text { prodromal } \\
\text { signs \& } \\
\text { symptoms } \\
>\text { Emergency }\end{array}$ & $\begin{array}{l}>\text { Problem Solving } \\
>\text { Role Playing } \\
>\text { Questioning }\end{array}$ & $\begin{array}{l}\text { Case Scenario- } \\
\text { role playing }\end{array}$ \\
\hline
\end{tabular}


A Gender Specific Educational 74

\begin{tabular}{|l|l|l|l|}
\hline & \multicolumn{1}{|c|}{$\begin{array}{l}\text { response } \\
\text { procedure }\end{array}$} & & \\
\hline & & & \\
\hline $\begin{array}{l}\text { 3. By the end } \\
\text { of class, list 4-5 } \\
\text { types of } \\
\text { information to } \\
\text { give the 911 } \\
\text { operator }\end{array}$ & $>\begin{array}{l}\text { Discuss info } \\
\text { the operate } \\
\text { may ask } \\
\text { How to answer } \\
\text { questions } \\
\text { It's alright to } \\
\text { feel scared }\end{array}$ & $>$ Discussion & $\begin{array}{l}\text { Case Scenario- } \\
\text { role playing }\end{array}$ \\
\hline & & & \\
\hline
\end{tabular}


A Gender Specific Educational 75

Appendix F

Pre and Post Tests, Sessions 1-4 


\section{Pre and Post Tests, Sessions 1-4}

Pre/Post-Test : Session \# 1

Passcode:

Age:

Ethnicity:

Occupation:

City you live:

1. Define Heart Disease (HD) in one or two sentences.

2. Define Coronary Heart Disease (CHD) in one or two sentences.

3. What is the number killer in the US?

4. What is the most common type of Heart Disease?

5. What is atherosclerosis?

6. List risk factors of heart disease that can't be changed by changing your lifestyle

7. List risk factors of heart disease that you can change by changing your lifestyle

8. How does coronary heart disease lead to a heart attack?

9. What is angina?

10. What is the difference between stable and unstable angina? 
Pre/Post Test, session 2

Heart Disease- Risk Factors

Passcode

Age

Race

Education level

Town you live

1. List all the risk factors of heart disease

2. List the risk factors that can be controlled by lifestyle changes or by taking a medication

3. List the risk factors that can not be controlled by lifestyle changes or medications

4. What is

BMI?

5. Do you know your cholesterol?

6. How does diabetes impact heart disease? 
Pre/Post Test, Session 3

Passcode

Heart Disease- How to Protect Yourself

Age

Race

Education level

Town you live

1. List 3-5 ways you can help lower your risk of heart disease

2. List all types of fat

3. Identify 3 foods that are high in saturated fats

4. Give an example of an unsaturated fat

5. You can eat as much unsaturated fat as you would like T or $\mathrm{F}$

6. List foods high in transfats

7. Foods made with hydrogenated oils are healthy $T$ or $\mathrm{F}$

8. Diets high in saturated fats are a major risk factor for heart disease? $\mathrm{T}$ or $\mathrm{F}$

9. Diet and exercise can help reduce cholesterol levels? T or $\mathrm{F}$

10. Do you read labels before purchasing foods? Yes or No 
Pre/Post Test, Session 4

Passcode

Heart Disease- Signs \& Symptoms of Heart Attack

Age

Race

Education level

Town you live

7. List 3-5 more common signs and symptoms of a heart attack

8. List 3-5 less common signs and symptoms of a heart attack

9. Women and Men have the same symptoms of a heart attack T

or $\mathrm{F}$

10. Many women don't experience chest pain during a heart attack T

or $\mathrm{F}$

11. Symptoms of a heart attack can occur months, even years before the attack T or $\mathrm{F}$

12. List 3-5 symptoms that can occur months before a heart attack

13. What is the most common symptom of a heart attack in both men and women

14. Explain why it is important to recognize a heart attack early? 
15. What would you do if you, or someone you knew was having a heart attack?

16. List the steps of CPR

1.

2.

3.

4.

5 . 
A Gender Specific Educational 81

Appendix G

Program Evaluation Tool 


\section{Program Evaluation Tool}

Please rate the following aspects of the program and supply helpful comments for future courses

1-Poor 2-Fair 3-Effective 4-Very Effective

$\underline{5-\text { Excellent }}$

1. Welcome and Introduction:

2. Objectives met:

3. Speakers clear and effective:

4. Program content:

5. Program was well organized:

Comments:

What aspect of the program do you think needs improvement? 
What aspect of the program do you think was best developed?

Do you think the program is useful for participants at your level? 
A Gender Specific Educational 84

Appendix $\mathrm{H}$

Participants' Evaluation Comments 


\section{Participants' Evaluation Comments}

\begin{abstract}
Comments from evaluation of sessions
\end{abstract}

The speech was quick and to the point

The session was useful and informative Speaker was clear and effective Having this again but with more time Handouts were to the point, self explanatory Very informative, learned things I didn't know before Loved the case scenarios for clearer visual of someone having a heart attack Well spoken with information lay out in order and to the point Interesting to know how we really need to read labels of foods we are eating The section on women's symptoms of a heart attack was very useful Great teacher

Learned a lot about the course, very interesting and very effective The speaker was very well organized and very informative The best part was in how heart disease affects women Very interesting and educational More time and better pictures, maybe ones in color 